\title{
Muscles of mice deficient in $\alpha$-sarcoglycan maintain large masses and near control force values throughout the life span
}

\author{
Christina M. Consolino, ${ }^{1,2}$ Franck Duclos, ${ }^{3}$ Jane Lee, ${ }^{3}$ \\ Roger A. Williamson, ${ }^{4}$ Kevin P. Campbell, ${ }^{3}$ and Susan V. Brooks ${ }^{1,2}$ \\ ${ }^{1}$ Institute of Gerontology and ${ }^{2}$ Department of Molecular and Integrative Physiology, \\ University of Michigan, Ann Arbor, Michigan; and ${ }^{3}$ Howard Hughes Medical Institute \\ and ${ }^{4}$ Department of Obstetrics and Gynecology, University of Iowa, Iowa City, Iowa
}

Submitted 27 December 2004; accepted in final form 3 May 2005

\begin{abstract}
Consolino, Christina M., Franck Duclos, Jane Lee, Roger A. Williamson, Kevin P. Campbell, and Susan V. Brooks. Muscles of mice deficient in $\alpha$-sarcoglycan maintain large masses and near control force values throughout the life span. Physiol Genomics 22: 244-256, 2005. First published May 10, 2005; 10.1152/physiolgenomics.00311.2004. $\alpha$-Sarcoglycan-deficient (Sgca-null) mice provide potential for elucidating the pathogenesis of limb girdle muscular dystrophy type 2D (LGMD 2D) as well as for studying the effectiveness of therapeutic strategies. Skeletal muscles of Sgca-null mice demonstrate an early onset of extensive fiber necrosis, degeneration, and regeneration, but the progression of the pathology and the effects on muscle structure and function throughout the life span are not known. Thus the phenotypic accuracy of the Sgca-null mouse as a model of LGMD 2D has not been fully established. To investigate skeletal muscle structure and function in the absence of $\alpha$-sarcoglycan throughout the life span, we analyzed extensor digitorum longus and soleus muscles of male and female Sgca-null and wild-type mice at 3, 6, 12, and 18 mo of age. Maximum isometric forces and powers were measured in vitro at $25^{\circ} \mathrm{C}$. Also determined were individual myofiber cross-sectional areas and numbers, water content, and the proportion of the cross section occupied by connective tissue. Muscle masses were 40-100\% larger for Sgca-null compared with age- and gender-matched wild-type mice, with the majority of the increased muscle mass for Sgca-null mice attributable to greater connective tissue and water contents. Although the greater mass of muscles in $\mathrm{Sgca}$-null mice was primarily noncontractile material, absolute forces and powers were maintained near control levels at all ages, indicating a successful adaptation to the deficiency in $\alpha$-sarcoglycan not observed at any age in LGMD 2D patients.
\end{abstract}

muscular dystrophy; limb muscles; contractility; aging

ALPHA-SARCOGLYCAN is one of at least five glycoproteins that form a functional subcomplex within the dystrophin-glycoprotein complex (DGC) of skeletal muscle. The DGC forms a link between cytoskeletal actin and laminin 2 in the extracellular matrix (23) that is critical for maintaining the integrity of the muscle fiber plasma membrane $(32,37,53)$. The function of the sarcoglycans is not known, but they may serve a mechanical role (43) or act as receptor molecules in cell signaling (7, 13). A deficiency of $\alpha$-sarcoglycan results in reductions in the remaining components of the $\operatorname{DGC}(19,34,51)$ and leads to limb girdle muscular dystrophy (LGMD) type 2D $(34,46)$. The disease appears to affect males and females with approximately equal incidence with a clinical course that varies strikingly,

Article published online before print. See web site for date of publication (http://physiolgenomics.physiology.org).

Address for reprint requests and other correspondence: S. V. Brooks, Institute of Gerontology, Univ. of Michigan, 300 N. Ingalls Bldg., Ann Arbor, MI 48109-2007 (E-mail: svbrooks@umich.edu). correlated in part with the type of mutation and the amount of residual protein $(34,51)$. The unifying features of type 2 LGMDs are autosomal recessive inheritance, elevated serum creatine kinase levels, and preferential weakness of pelvic and shoulder girdle muscles (21). For individuals with complete $\alpha$-sarcoglycan deficiency, clinical presentation and progression overlap significantly with dystrophin-deficient Duchenne muscular dystrophy (DMD) with the onset during early childhood of symptoms including difficulty walking and demonstration of Gowers' sign $(34,51)$. These individuals generally become wheelchair bound by about 15 years of age with subsequent evolution to respiratory insufficiency $(20,34)$.

Similar to the histopathology observed in the muscles of patients with LGMD (51), skeletal muscles from $\alpha$-sarcoglycan-deficient (Sgca-null) mice show an early onset of extensive fiber necrosis and evidence of degeneration and regeneration (19). Despite knowledge of these early skeletal muscle pathologies in Sgca-null mice, the progression of the pathology and the effects on muscle structure and function throughout the life span are not known. Thus, while Sgca-null mice provide a potential means for studying the role of the protein in the pathophysiology of LGMD 2D as well as for evaluating the effectiveness of therapeutic strategies, the phenotypic accuracy of the Sgca-null mouse as a model of LGMD 2D has not been fully established.

Masses of extensor digitorum longus (EDL) and soleus muscles of Sgca-null mice are $50 \%$ and $70 \%$ greater, respectively, than muscles of wild-type (WT) littermates at $8 \mathrm{wk}$ of age, but absolute force is not comparably increased (19). Low specific forces [normalized for muscle cross-sectional area (CSA)] for $\alpha$-sarcoglycan-deficient muscles indicate that the elevated mass largely represents pseudohypertrophy rather than true physiological hypertrophy (47). Impairments in specific force may also result from a direct effect of the absence of $\alpha$-sarcoglycan on force generation (43). Our purpose was to examine limb muscles of Sgca-null mice to assess the changes in skeletal muscle structure-function relationships with aging and to determine whether the deficiency in $\alpha$-sarcoglycan affects skeletal muscle in males and females differently. The progressive degenerative nature of LGMD 2D (34) along with the evidence of degeneration and regeneration in young Sgcanull mice (19) suggested that muscles of Sgca-null mice would demonstrate an accelerated loss of mass and force with age compared with muscles of WT mice. Consequently, we hypothesized that EDL and soleus muscles of young Sgca-null mice are larger but generate lower specific forces than those of WT mice, whereas the muscles of old Sgca-null mice are both smaller and generate lower specific forces. 


\section{METHODS}

\section{Animals}

The methods for breeding the Sgca-null mice have been described previously (19). For several weeks before experimentation, specific pathogen-free (SPF) male and female Sgca-null and WT (mixed background) mice were housed in an SPF facility in the Unit for Laboratory Animal Medicine at the University of Michigan. All procedures were conducted in accordance with the National Institutes of Health Guide for the Care and Use of Laboratory Animals (NIH Pub. No. 85-23) and were approved by the University of Michigan Committee on the Use and Care of Animals. The survival characteristics of Sgca-null mice have not been established. High mortality rates after 18 mo of age necessitated a cohort of 21 mice to obtain a sample of 13 mice for evaluation at $18 \mathrm{mo}$. Therefore, 18 mo was estimated to be the $\sim 50 \%$ survival point and was chosen as the oldest age at which $\mathrm{Sgca}$-null mice would be evaluated. A total of 41 Sgca-null mice and 37 WT mice distributed evenly between males and females was analyzed at $3,6,12$, and 18 mo.

\section{Operative Procedures}

Mice were anesthetized with an initial intraperitoneal injection of avertin $(400 \mathrm{mg} / \mathrm{kg})$ with supplemental injections given to maintain an adequate level of anesthesia during the dissection of the hindlimb muscles. In most cases, experiments were conducted on the EDL and soleus muscles of both the right and left legs for each mouse. A total of 81 EDL muscles and 80 soleus muscles of Sgca-null mice was analyzed. For WT mice, 74 EDL muscles and 74 soleus muscles were evaluated. Each muscle was isolated, and a 5-0 silk suture was tied securely to the distal and proximal tendons. The muscle was then removed from the animal and placed in a horizontal bath containing buffered mammalian Ringer solution [composed of (in $\mathrm{mM}$ ) 137 $\mathrm{NaCl}, 24 \mathrm{NaHCO}_{3}, 11$ glucose, $5 \mathrm{KCl}, 2 \mathrm{CaCl}_{2}, 1 \mathrm{MgSO}_{4}, 1$ $\mathrm{NaH}_{2} \mathrm{PO}_{4}$, and 0.025 turbocurarine chloride] maintained at $25^{\circ} \mathrm{C}$ and bubbled with $95 \% \mathrm{O}_{2}-5 \% \mathrm{CO}_{2}$ to stabilize $\mathrm{pH}$ at 7.4. One tendon of the muscle was tied securely to a force transducer (model BG-50, Kulite Semiconductor Products), and the other tendon was secured to the lever arm of a servomotor (model 305B, Aurora Scientific; Aurora, Ontario, Canada). After removal of the muscles, animals were euthanized with an overdose of anesthetic and administration of a pneumothorax.

\section{Measurement of Contractile Properties}

Muscles were stimulated between two stainless steel plate electrodes. The voltage of single $0.2-\mathrm{ms}$ stimulation pulses was adjusted to give a maximum isometric twitch. Subsequently, muscle length was adjusted to the optimal length $\left(L_{\mathrm{o}}\right)$ at which twitch force was maximal (11). The forces developed by EDL and soleus muscles were recorded during 300- or 900-ms trains of stimulation pulses, respectively, and stimulation frequency was increased until the maximum isometric tetanic force $\left(\mathrm{P}_{\mathrm{o}}\right)$ was achieved. A stimulus frequency of $\sim 160 \mathrm{~Hz}$ was typically needed to achieve $\mathrm{P}_{\mathrm{o}}$ for EDL muscles, and for soleus muscles $\sim 140 \mathrm{~Hz}$ elicited $\mathrm{P}_{\mathrm{o}}$. No changes in the stimulus frequencies that resulted in $\mathrm{P}_{\mathrm{o}}$ were observed with aging for either $\mathrm{Sgca}$-null or WT mice.

For each muscle, optimum fiber length $\left(L_{\mathrm{f}}\right)$ was calculated by multiplying $L_{\mathrm{o}}$ by $L_{\mathrm{f}} / L_{\mathrm{o}}$ for EDL and soleus muscle of 0.45 and 0.71 , respectively (11). Power output was determined during isovelocity shortenings through $10 \%$ of $L_{\mathrm{f}}$. Equal portions of the shortening ramp occurred above and below $L_{\mathrm{o}}$. Stimulation at the frequency that resulted in $\mathrm{P}_{\mathrm{o}}$ and shortening were initiated simultaneously, and stimulation was terminated at the end of the $10 \%$ shortening ramp. Power was calculated as the product of the average force developed during the shortening ramp and the velocity of shortening. A range of velocities was tested to find the optimum velocity $\left(V_{\mathrm{o}}\right), \sim 1.7 L_{\mathrm{f}} / \mathrm{s}$ and
$0.6 L_{\mathrm{f}} / \mathrm{s}$ for EDL and soleus muscles, respectively, at which the power output was maximal.

\section{Morphological Measures}

After in vitro measurements, the muscle was removed from the bath, the tendons were trimmed, and the muscle was blotted and weighed. Total fiber CSA was calculated by dividing the muscle mass (in $\mathrm{mg}$ ) by the product of $L_{\mathrm{f}}$ (in $\mathrm{mm}$ ) and the density of mammalian skeletal muscle, $1.06 \mathrm{~g} / \mathrm{cm}^{2}$. Specific $\mathrm{P}_{\mathrm{o}}$ (in $\mathrm{kN} / \mathrm{m}^{2}$ ) was calculated by dividing $\mathrm{P}_{\mathrm{o}}$ by total fiber CSA for each muscle. Maximum power was normalized by muscle mass. Muscles were quick frozen in isopentane cooled by dry ice and stored at $-80^{\circ} \mathrm{C}$. A subset of muscles was used to determine the ratio of dry mass to wet mass. To assess this parameter, the muscle was cut in half, and the wet mass of each half was obtained. One half was frozen, whereas the other half was dried overnight at $60^{\circ} \mathrm{C}$ and weighed again to allow calculation of the dry mass-to-wet mass ratio.

Frozen cross sections of $10 \mu \mathrm{m}$ thickness were cut from the widest portion of the belly of each muscle. Cryosections were mounted on microscope slides and stained with either hematoxylin (nuclear stain) and eosin-phloxine (cytoplasmic stain) (H\&E) or Sirius red (connective tissue stain). Slides were stained in Sirius red for $1 \mathrm{~h}$ and then washed $2 \times 2 \mathrm{~min}$ in acetic acid water, $2 \times 1 \mathrm{~min}$ in $100 \%$ and $95 \%$ ethanol, and $2 \times 1 \mathrm{~min}$ in xylene (54). Stained sections were visualized on a microscope (Leitz Laborlux, Leica; Wetzlar, Germany) and captured with a video camera (Diagnostic Instruments; Sterling Heights, MI) using the BioQuant image-analysis system (Nashville, TN).

For each muscle, individual fiber CSAs were evaluated from a single field of an H\&E-stained cross section at $\times 400$ magnification. Fields containing $\sim 50$ fibers were chosen randomly from the central portion of the muscle avoiding fields that reached the edge of the section. Images of between six and eight EDL and soleus muscles from 6-, 12-, and 18-mo-old male and female Sgca-null and WT mice were analyzed. Consequently, single fiber areas were measured for 300-400 fibers for each experimental group. The total numbers of fibers in cross sections were counted for five EDL and soleus muscles of animals at 3,12 , and 18 mo of age. For total fiber counts, cross sections were viewed at $\times 100$ with approximately six frames required to view the entire muscle cross section. The numbers of muscle fibers with central nuclei were also counted for four randomly chosen fields from a total of 173 muscles distributed among the 3 age groups.

To assess the presence of split or branched fibers, anterior tibialis (ATB) muscles from young, adult, and old Sgca-null and WT mice were harvested and digested over night in $15 \%$ nitric acid (8). After $24 \mathrm{~h}$, nitric acid was washed from the specimens, which were subsequently stored in a solution containing equal parts glycerol and $0.2 \% \mathrm{SDS}$. Isolated fibers were teased from digested muscles with fine forceps and transferred to slides covered with glycerol for microscopic examination $(\times 100)$ for the presence of branching or splitting.

To minimize observer bias in determining the percentage of connective tissue present in each muscle cross section, Scion Image (Scion; Frederick, MD) was used to estimate the Sirius red-stained areas of cross sections. Images of four random fields at $\times 100$ were captured on the BioQuant system under identical conditions. Each image was imported into Microsoft Photodraw (Microsoft; Redmond, WA), and the same brightness and contrast settings were applied to include only those areas stained by Sirius red. Grayscale images were then imported into Scion Image to determine the 256 gray level counts. MatLab 12 (Mathworks; Natick, MA) was used to calculate the percentage of the cross section positive for Sirius red. For both Sgca-null and WT mice, a minimum of four muscles per age group was analyzed. 
Table 1. Summary of results of three-factor ANOVA

\begin{tabular}{|c|c|c|c|c|c|c|c|c|c|c|c|c|c|}
\hline Factor & Body Mass & \multicolumn{2}{|c|}{ Muscle Mass } & \multicolumn{2}{|c|}{$\mathrm{Po}_{\mathrm{o}}$} & \multicolumn{2}{|c|}{ Specific $P_{o}$} & \multicolumn{2}{|c|}{ Maximum Power } & \multicolumn{2}{|c|}{ Normalized Power } & \multicolumn{2}{|c|}{$V_{\mathrm{o}}$} \\
\hline $\mathrm{S}$ & $0.00 *$ & $0.00 *$ & $0.00^{*}$ & $0.00 *$ & 0.06 & $0.00 *$ & $0.00^{*}$ & $0.00^{*}$ & $0.00^{*}$ & $0.00 *$ & 0.31 & 0.31 & $0.01 *$ \\
\hline A & $0.00^{*}$ & $0.003 *$ & 0.19 & $0.0001 *$ & $0.001 *$ & 0.053 & 0.12 & 0.15 & $0.01 *$ & 0.32 & $0.003 *$ & $0.02 *$ & 0.057 \\
\hline $\mathrm{S} \times \mathrm{G}$ & 0.20 & 0.08 & 0.11 & 0.86 & $0.0003 *$ & 0.78 & $0.0001 *$ & 0.20 & $0.0004 *$ & 0.97 & $0.01 *$ & 0.95 & 0.055 \\
\hline $\mathrm{S} \times \mathrm{A}$ & $0.00 *$ & $0.01 *$ & 0.47 & $0.02 *$ & $0.001 *$ & 0.85 & 0.055 & 0.40 & 0.98 & 0.99 & 0.78 & 0.39 & 0.61 \\
\hline
\end{tabular}

$P$ values showing the main effects of strain(s), gender $(\mathrm{G})$, and age $(\mathrm{A})$ of mice as well as $\mathrm{S} \times \mathrm{G}, \mathrm{S} \times \mathrm{A}, \mathrm{G} \times \mathrm{A}$, and $\mathrm{S} \times \mathrm{G} \times \mathrm{A}$ interactions are shown. EDL, extensor digitum longus muscle; SOL, soleus muscle; $\mathrm{P}_{\mathrm{o}}$, maximum isometric force; $V_{\mathrm{o}}$, optimal velocity. * Significant effects.

\section{Statistical Analysis and Data Presentation}

All data are presented as means \pm SE. For muscle mass and muscle contractile properties, three-way ANOVAs were used to determine the primary effects of age, gender, and strain as well as second- and third-order interactions. For these and all subsequent analyses, differences were accepted as being significant if $P<0.05$. The results of the ANOVAs are summarized in Table 1 . No variable included in this analysis showed a significant gender $\times$ age interaction, and for only a single variable $\left(\mathrm{P}_{\mathrm{o}}\right)$ for one muscle (EDL) was the third-order term (strain $X$ gender $\times$ age) significant. These observations support the conclusion that overall the effects of age were not different for muscles of male and female mice. Therefore, for clarity of presentation, data from male and female mice are displayed separately, and asterisks in the figures indicate strain differences only, i.e., between Sgca-null and WT mice. Because the effect of the $\alpha$-sarcoglycan deficiency on the extent of muscle hypertrophy was not different between male and female mice, gender effects on the detailed morphological data were not analyzed, and the effects of age and strain were determined separately for males and females by two-way ANOVA. Finally, because of extremely low numbers of fibers in muscles of WT mice containing central nuclei, gender and age effects on central nuclei were analyzed only for $S g c a$-null mice by two-way ANOVA. When significance was detected, Tukey's post hoc comparison was used to assess the difference. For single fiber CSA, the data were not normally distributed. Consequently, cumulative frequency distributions of fiber sizes for each experimental group were determined, and nonparametric statistical analyses were employed. Finally, variability coefficients were calculated for fiber CSA for each muscle by multiplying the standard deviation of the measurements by 1,000 and dividing by the mean fiber CSA (25).

\section{RESULTS}

\section{Body Masses}

For body mass and for the masses of EDL and soleus muscles, strain $\times$ gender interactions were not observed (Table 1). Body masses of both male and female WT mice increased $\sim 50 \%$ between 3 and 12 mo of age with no change between 12 and 18 mo (Fig. 1). In contrast, Sgca-null mice were 25\% larger than WT mice at 3 mo of age, yet neither male nor female Sgca-null mice showed any change in body mass with age. As a result, older Sgca-null mice were 20-25\% smaller than age-matched WT mice (Fig. 1).

\section{Muscle Masses}

Despite increasing body masses of WT mice, the masses of EDL (Fig. 2A) and soleus (Fig. 2B) muscles were unchanged from 3 to 18 mo. The increasing body masses without corresponding increases in muscle masses resulted in decreasing muscle mass-to-body mass ratios (Fig. 2, $C$ and $D$ ) and suggest that lean body mass remains stable in WT mice throughout the life span with increases in body mass due to increased adiposity. Also unchanged between 3 and 18 mo was soleus muscle mass (Fig. 2B) and muscle mass-to-body mass ratio (Fig. 2D) for Sgca-null mice, but EDL muscle mass increased for both male and female Sgca-null mice up to 12 mo of age (Fig. 2A) as did the EDL muscle mass-to-body mass ratio (Fig. $2 C$ ).

At all ages, EDL and soleus muscle masses and muscle mass-to-body mass ratios were larger for Sgca-null mice than for gender-matched WT mice. The lack of change with age in EDL muscle mass in WT mice coupled with the increasing mass in Sgca-null mice resulted in EDL muscles of Sgca-null mice that were $50 \%$ larger than WT at 3 mo and over $100 \%$ larger at $18 \mathrm{mo}$ (Fig. 2A). From 3 to $18 \mathrm{mo}$, soleus muscles of Sgca-null mice maintained an average $42 \% \pm 4 \%$ greater mass than those of WT mice (Fig. 2B). For both EDL and soleus muscles, the effect of the $\alpha$-sarcoglycan deficiency on muscle mass was not different between male and female mice (Fig. 2).

The large muscle masses for Sgca-null mice were not restricted to EDL and soleus muscles. For 6-mo-old mice, masses of six additional muscles were measured, including ATB, gastrocnemius (GTN), plantaris, quadriceps, hamstrings, and

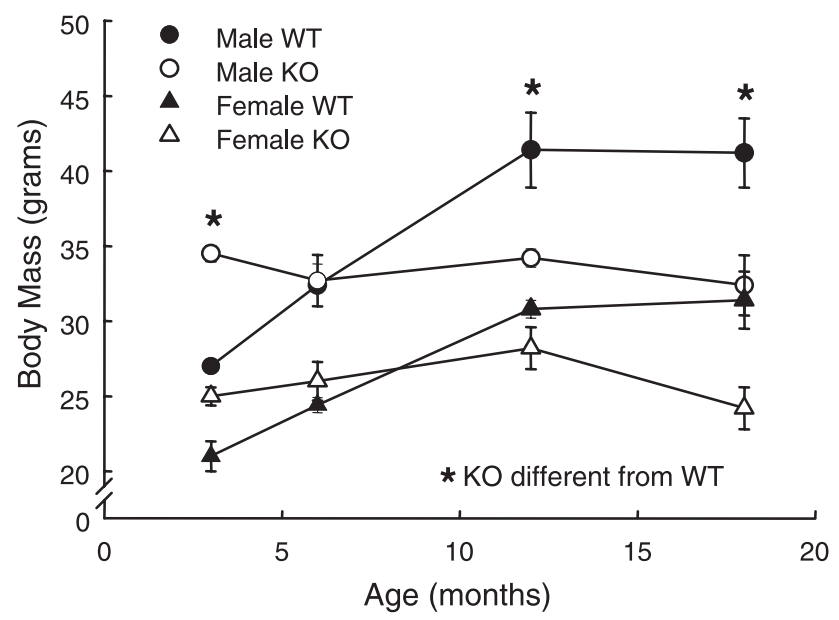

Fig. 1. Body masses of male and female $\alpha$-sarcoglycan-deficient (Sgca-null) knockout (KO) and wild-type (WT) mice. Values are given as means \pm SE for body masses (in g) of male and female KO and WT mice at 3, 6, 12, and 18 mo of age. No effect of age was demonstrated in KO mice, whereas WT mice increased in mass up to 12 mo. There were no significant strain $\times$ gender or gender $\times$ age interactions. *Significant differences between data on genderand age-matched KO and WT mice $(P<0.05)$. 
A

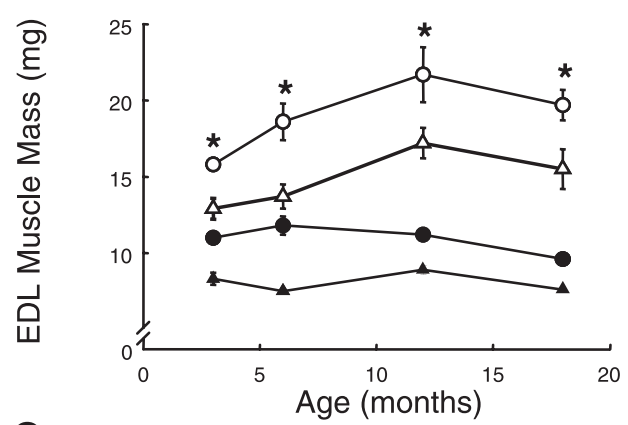

C

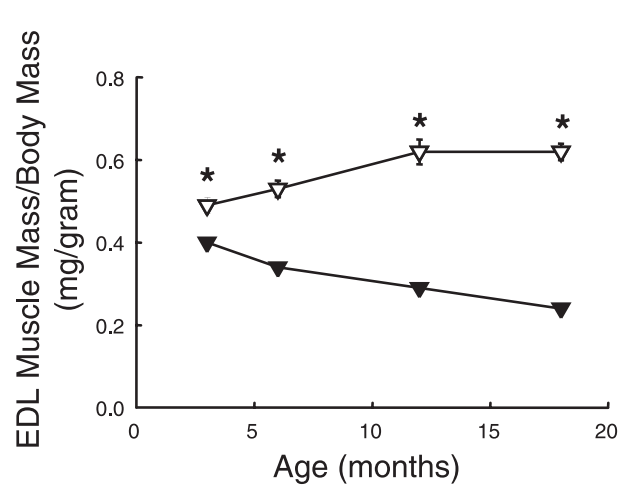

B
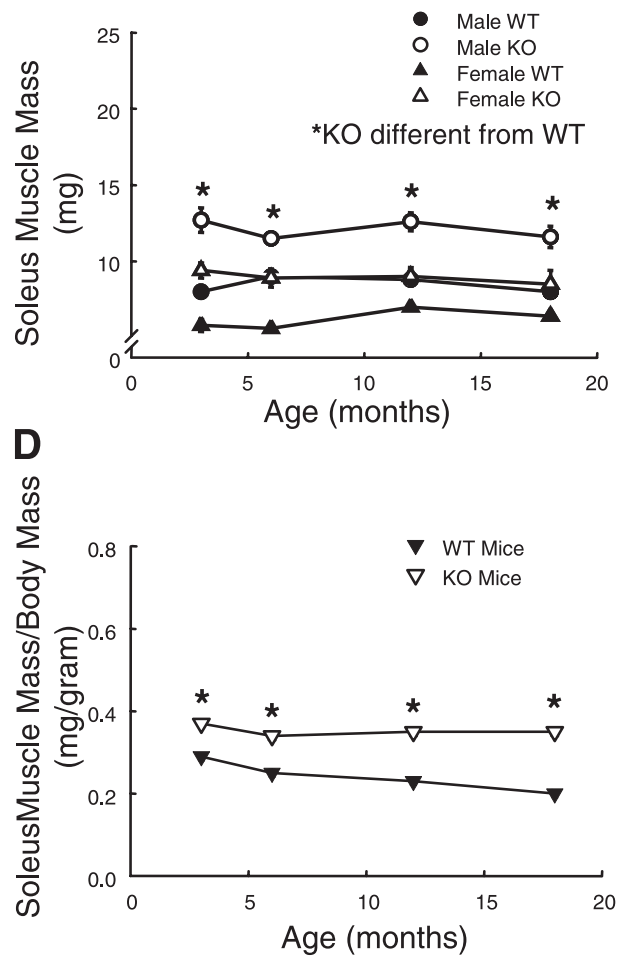

Fig. 2. Muscle masses of Sgca-null (KO) and WT mice. Values are given as means \pm SE for masses (in $\mathrm{mg}$ ) of extensor digitorum longus (EDL; $A$ ) and soleus muscles $(B)$ of male and female $\mathrm{KO}$ and WT mice at various ages. No effects of age were demonstrated for EDL or soleus muscles of WT mice or for soleus muscles in $\mathrm{KO}$ mice, whereas EDL muscle mass in $\mathrm{KO}$ mice increased out to 12 mo. There were no significant strain $\times$ gender or gender $\times$ age interactions. Muscle masses of EDL $(C)$ and soleus muscles $(D)$ of $\mathrm{KO}$ and WT mice are also shown expressed relative to body mass. No main effects of gender were observed nor were there any significant strain $\times$ gender or gender $\times$ age interactions. Consequently, data for male and female mice were pooled. For both EDL and soleus muscles of WT mice, muscle mass/ body mass decreased with age out to $12 \mathrm{mo}$, whereas for $\mathrm{KO}$ mice, the muscle mass/body mass increased for EDL muscles to $12 \mathrm{mo}$ and remained unchanged by age for soleus muscles. *Values for KO mice were greater $(P<0.05)$ than those of WT mice for both muscles at every age. latissimus dorsi muscles (Fig. 3). All muscles except GTN had larger masses in Sgca-null mice. For ATB muscles, the effect of the $\alpha$-sarcoglycan deficiency on muscle mass was restricted to male mice. Despite the lack of an effect of $\alpha$-sarcoglycan deficiency on GTN muscle mass or on ATB muscles of female mice, overall, muscles of Sgca-null mice were on average 38\% $\pm 2 \%$ larger than muscles of WT mice. The nearly $40 \%$ greater mass for muscles of Sgca-null compared with WT mice at 6 mo

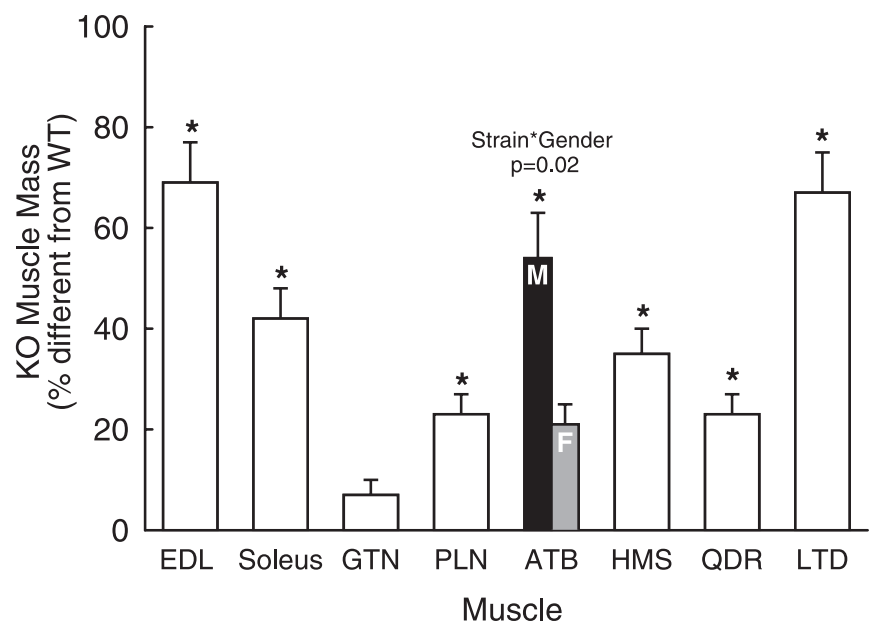

Fig. 3. Muscle masses of Sgca-null (KO) mice. Values are given as means \pm SE for EDL, soleus, gastrocnemius (GTN), plantaris (PLN), tibialis anterior (ATB), hamstrings (HMS), quadriceps (QDR), and latissimus dorsi (LTD) muscle masses expressed as the percent different from WT values at 6 mo of age. Strain $\times$ gender interactions were observed for ATB muscles, so data for males (M; solid bar) and females (F; shaded bar) are shown separately. For the remaining muscles, data for males and females were pooled. *Significant differences between data on age-matched KO and WT mice $(P<0.05)$. of age with no difference in body mass between the two strains of mice necessitates a lower mass of either other muscles or of nonmuscle tissues in Sgca-null mice.

\section{EDL Muscle Contractile Properties}

Consistent with no change with age in mass (Fig. 2A) or in total fiber CSA (data not shown) of EDL muscles of male or female WT mice, the $\mathrm{P}_{\mathrm{o}}$ (Fig. 4A) and absolute power (Table 2) did not change between 3 and 18 mo of age. In contrast, $\mathrm{P}_{\mathrm{o}}$ for EDL muscles of Sgca-null mice showed a complex relationship with age. In male Sgca-null mice, as EDL muscle mass increased, $\mathrm{P}_{\mathrm{o}}$ tended to increase, but only reached significance at $18 \mathrm{mo}$ (Fig. 4A). $\mathrm{P}_{\mathrm{o}}$ also increased somewhat in female Sgca-null mice from 3 to 12 mo but then decreased $\sim 25 \%$ between 12 and 18 mo (Fig. 4A). Even with the $25 \%$ decrease in $\mathrm{P}_{\mathrm{o}}$ between 12 and 18 mo for EDL muscles of female Sgca-null mice, $\mathrm{P}_{\mathrm{o}}$ was maintained at or slightly above WT values at each age studied for both male and female Sgca-null mice (Fig. 4A). Because of a lack of any significant strain effects on $V_{\mathrm{o}}$, absolute power for EDL muscles of Sgca-null mice mirrored the isometric force with values not different from WT at 6 mo and $\sim 25 \%$ greater at 12 and 18 mo in both males and females (Table 2). No significant age effects were observed for EDL muscles for either specific $\mathrm{P}_{\mathrm{o}}$ normalized by total fiber CSA (Fig. 5A) or power normalized by mass (Table 2). Whereas the EDL muscles of both male and female Sgcanull mice exhibited modest elevations in $\mathrm{P}_{\mathrm{o}}$ and absolute power compared with WT mice, the much greater CSA and masses of the muscles of Sgca-null mice resulted in specific $\mathrm{P}_{\mathrm{o}}$ (Fig. 5A) and normalized power (Table 2) values that were $30 \%$ lower than those for WT mice. 
Fig. 4. Maximum isometric force $\left(\mathrm{P}_{\mathrm{o}}\right)$ for EDL and soleus muscles of Sgca-null (KO) and WT mice. Values are given as means \pm $\mathrm{SE}$ for $\mathrm{P}_{\mathrm{o}}($ in $\mathrm{mN}$ ) for $\mathrm{EDL}(A)$ and soleus muscles $(B)$ of male and female KO and WT mice. No effects of age were demonstrated for male or female WT mice for either EDL or soleus muscles. For male $\mathrm{KO}$ mice, $\mathrm{P}_{\mathrm{o}}$ for EDL muscles was greater at 18 mo than at 3 mo, and for female $\mathrm{KO}$ mice, $\mathrm{P}_{\mathrm{o}}$ peaked at 12 mo followed by a decline. $\mathrm{P}_{\mathrm{o}}$ for soleus muscles was significantly elevated for both male and female KO mice at 3 mo. *Significant differences between data on agematched and gender-matched $\mathrm{KO}$ and WT mice $(P<0.05)$.
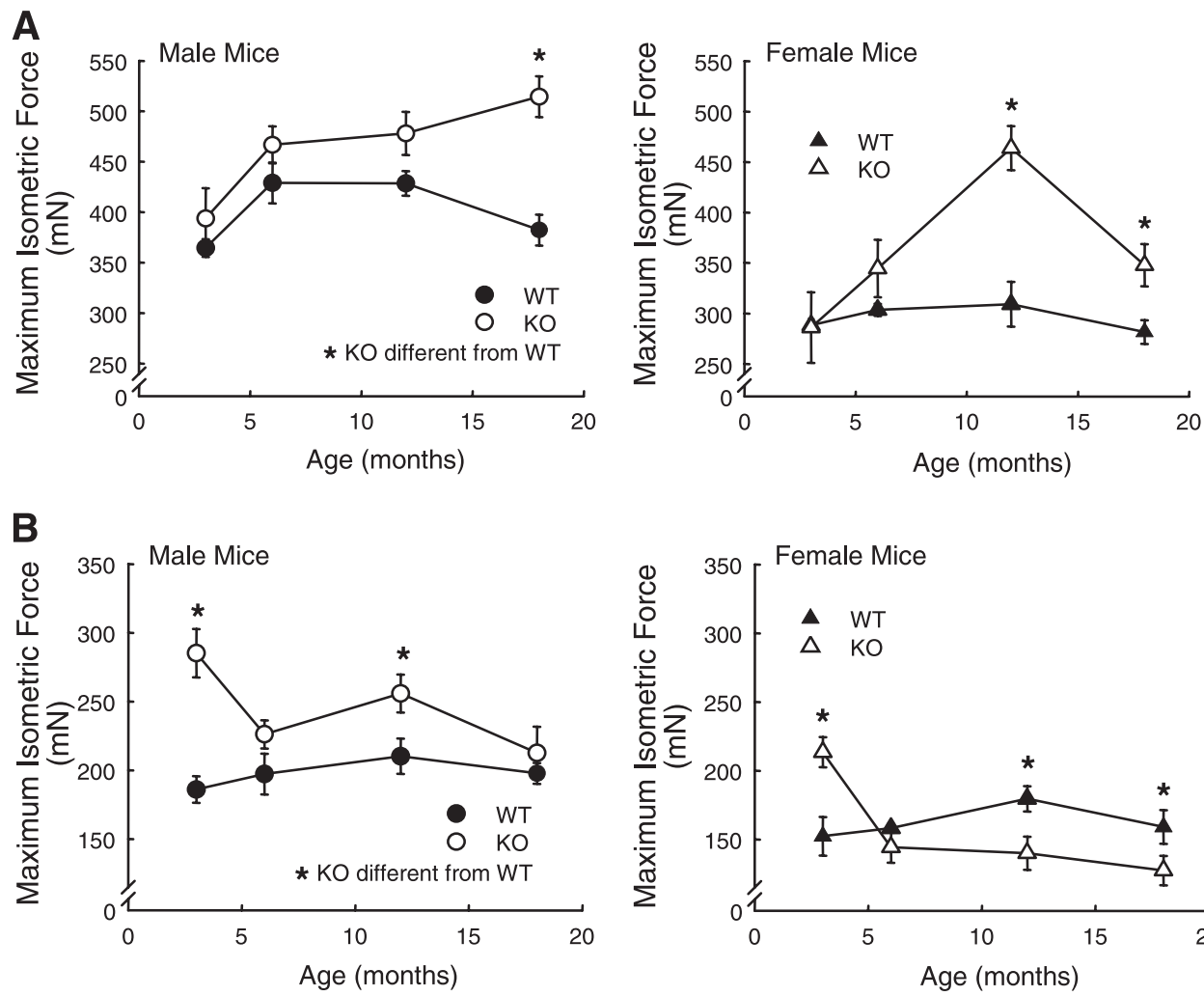

For none of the EDL muscle contractile properties was there a significant strain $\times$ gender interaction (Table 1), indicating that the $\alpha$-sarcoglycan deficiency had similar effects on EDL muscles of male and female mice, although for $\mathrm{P}_{\mathrm{o}}$ the thirdorder interaction was significant.

\section{Soleus Muscle Contractile Properties}

In contrast to the lack of strain $\times$ gender interactions for the contractile properties of EDL muscles, the $\alpha$-sarcoglycan deficiency had differing effects for soleus muscles of male and female mice on $\mathrm{P}_{\mathrm{o}}$, specific $\mathrm{P}_{\mathrm{o}}$, absolute power, and normalized power. Overall, strain $\times$ gender interactions can be summarized as indicating that soleus muscles of male mice adapted more effectively to the $\alpha$-sarcoglycan deficiency than those of female mice.
For soleus muscles of both male and female WT mice, $\mathrm{P}_{\mathrm{o}}$, like muscle mass, did not change between 3 and 18 mo of age (Fig. 4B). In contrast, in both male and female Sgca-null mice, $\mathrm{P}_{\mathrm{o}}$ decreased between 3 and 6 mo, after which $\mathrm{P}_{\mathrm{o}}$ was maintained out to 18 mo (Fig. 4B). Despite the decrease in soleus $P_{o}$ between 3 and 6 mo, $P_{o}$ was maintained at or slightly above WT values for male $\mathrm{SgCa}$-null mice at each age studied (Fig. $4 B$ ), whereas soleus muscles in female Sgca-null mice showed a $20 \%$ deficit in $\mathrm{P}_{\mathrm{o}}$ compared with WT values by 12 mo of age (Fig. 4B). Significant strain effects on $V_{\mathrm{o}}$ were observed, with $V_{\mathrm{o}}$ slightly greater for soleus muscles in $S g c a$-null compared with WT mice. The result for male mice was a $50 \%$ greater absolute power generated by soleus muscles of $S g c a$-null than WT mice (Table 2), and for soleus muscles of female Sgca-null mice, absolute powers were not different from WT values

Table 2. Maximum power of muscles of Sgca-null (KO) and WT mice

\begin{tabular}{|c|c|c|c|c|c|c|c|c|}
\hline & \multicolumn{2}{|c|}{ Male WT Mice } & \multicolumn{2}{|c|}{ Male KO Mice } & \multicolumn{2}{|c|}{ Female WT Mice } & \multicolumn{2}{|c|}{ Female KO Mice } \\
\hline $6 \mathrm{mo}$ & $1.62 \pm 0.09$ & $138 \pm 6$ & $1.89 \pm 0.13$ & $106 \pm 9 *$ & $0.99 \pm 0.06 \dagger$ & $133 \pm 9$ & $1.23 \pm 0.13 \dagger$ & $91 \pm 9^{*}$ \\
\hline $12 \mathrm{mo}$ & $1.50 \pm 0.07$ & $134 \pm 6$ & $1.92 \pm 0.14 *$ & $90 \pm 5^{*}$ & $1.07 \pm 0.09 \dagger$ & $121 \pm 9$ & $1.49 \pm 0.11$ & $87 \pm 6^{*}$ \\
\hline $18 \mathrm{mo}$ & $1.38 \pm 0.20$ & $142 \pm 20$ & $2.03 \pm 0.16^{*}$ & $102 \pm 7 *$ & $0.82 \pm 0.07 \dagger$ & $109 \pm 10 \dagger$ & $1.09 \pm 0.10$ & $71 \pm 5^{*}$ \\
\hline \multicolumn{9}{|c|}{ SOL muscles } \\
\hline $18 \mathrm{mo}$ & $0.23 \pm 0.02$ & $29 \pm 3$ & $0.39 \pm 0.06^{*}$ & $32 \pm 4$ & $0.14 \pm 0.03$ & $22 \pm 4$ & $0.13 \pm 0.02 \dagger$ & $15 \pm 2 \dagger$ \\
\hline
\end{tabular}

Values are means \pm SE. Sgca-null mice, $\alpha$-sarcoglycan-deficient [knockout $(\mathrm{KO})]$ mice; WT-mice, wild-type mice. $*$ Significant $(P<0.05)$ differences between data on age-matched and gender-matched KO and WT mice; † significant $(P<0.05)$ differences between data on male and female mice of the same age and strain. 

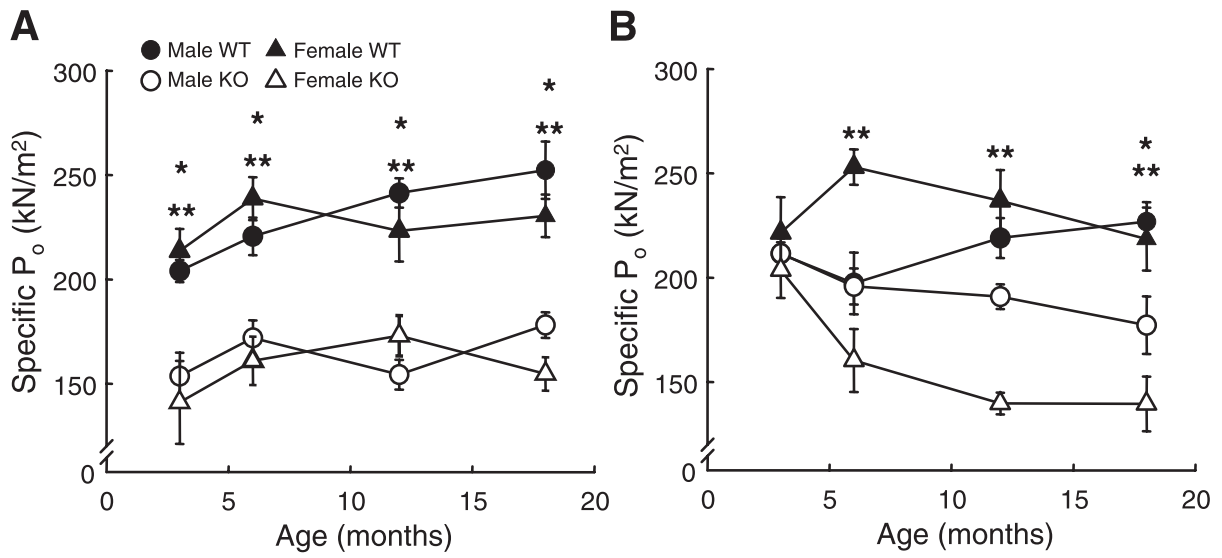

\begin{abstract}
Fig. 5. Specific $P_{o}$ for EDL and soleus muscles of Sgca-null (KO) and WT mice. Values are given as means $\pm \mathrm{SE}$ for $\mathrm{P}_{\mathrm{o}}$ normalized by muscle fiber cross-sectional area (CSA; specific $\mathrm{P}_{\mathrm{o}}$, in $\mathrm{kN} / \mathrm{m}^{2}$ ) of EDL $(A)$ and soleus muscles $(B)$ of male and female $\mathrm{KO}$ and WT mice at various ages. Specific $\mathrm{P}_{\mathrm{o}}$ for EDL muscles of male WT mice was greater at $18 \mathrm{mo}$ than at $3 \mathrm{mo}$, but there were no other age effects on specific $\mathrm{P}_{\mathrm{o}}$ for EDL or soleus muscles of male or female WT or KO mice. *Significant differences between data on age-matched male $\mathrm{KO}$ and WT mice $(P<0.05)$; **significant differences between data on agematched female KO and WT mice $(P<0.05)$.
\end{abstract}

*KO different from WT for male mice

$\star \star K O$ different from WT for female mice

(Table 2), despite a $20 \%$ lower $\mathrm{P}_{\mathrm{o}}$ (Fig. 4B). Thus, although $\mathrm{P}_{\mathrm{o}}$ was not maintained at WT values in all cases, adaptations in $V_{\mathrm{o}}$ resulted in absolute powers that reached at least WT values at each age studied. Preliminary analysis of pH-dependent histochemistry for myosin ATPase activity (data not shown) indicate that the greater $V_{\mathrm{o}}$ values for soleus muscles of Sgca-null compared with WT mice was associated with a shift to a larger percentage of fast fibers.

Specific $\mathrm{P}_{\mathrm{o}}$ of soleus muscles showed no overall age effects (Fig. 5B). As noted, soleus muscles of Sgca-null mice exhibited substantial elevations in $\mathrm{P}_{\mathrm{o}}$ compared with WT values at 3 mo of age (Fig. 4B), such that even when normalized by the much greater CSA of the muscles of Sgca-null mice, specific $\mathrm{P}_{\mathrm{o}}$ was not different for soleus muscles of Sgca-null and WT mice (Fig. 5B). Despite the decrease between 3 and 6 mo in $\mathrm{P}_{\mathrm{o}}$ for soleus muscles of male Sgca-null mice, the maintenance of $\mathrm{P}_{\mathrm{o}}$ at or above WT values resulted in soleus muscles showing significant deficits in specific $\mathrm{P}_{\mathrm{o}}$ only at $18 \mathrm{mo}$. In contrast, the decrease in $\mathrm{P}_{\mathrm{o}}$ for soleus muscles of female Sgca-null mice to a point $20 \%$ lower than WT values resulted in a $38 \pm 3 \%$ specific force deficit from 6 to 18 mo (Fig. $5 B$ ). Despite low specific forces, higher $V_{\mathrm{o}}$ values for muscles of $\mathrm{Sgca}$-null mice compensated as evidenced by normalized powers for both male and female Sgca-null mice that were not different from WT values at any age (Table 2).

\section{Histological Analyses}

EDL and soleus muscles of Sgca-null mice displayed histological evidence of extensive degeneration and regeneration
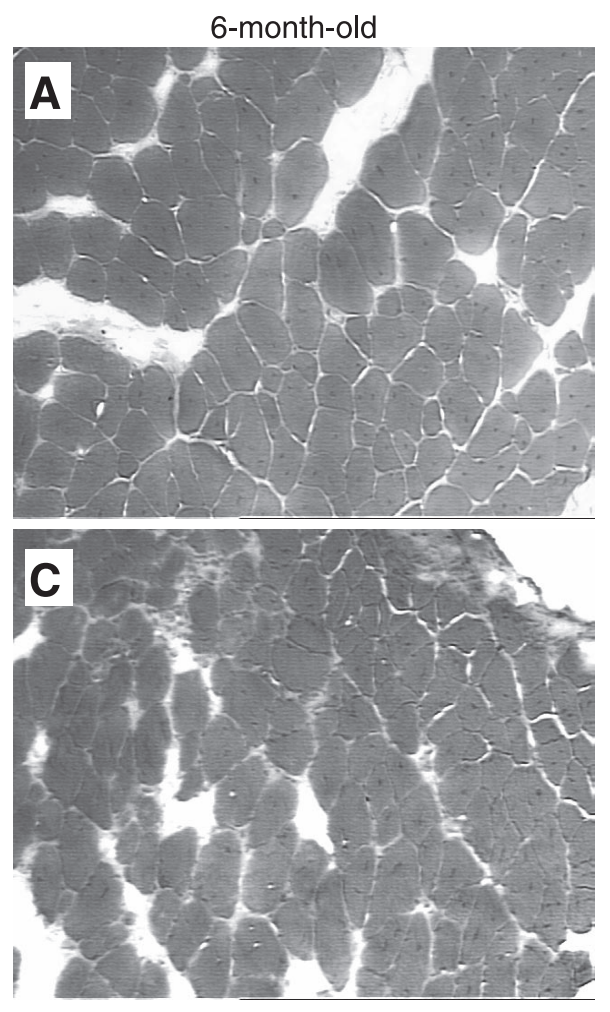
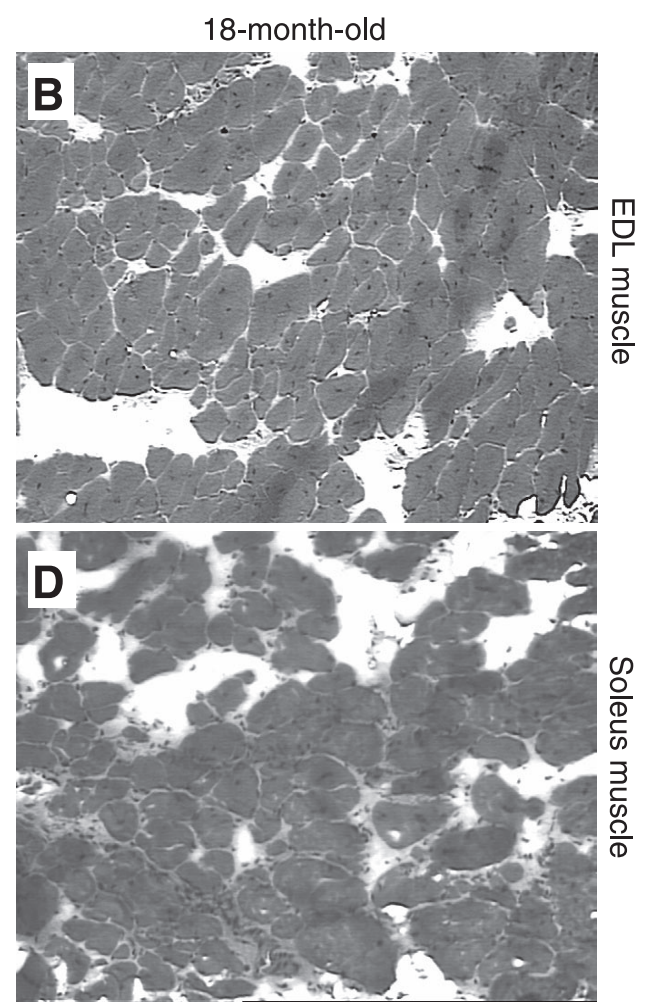

Fig. 6. Cross sections of muscles from $\mathrm{SgCa}$ null mice. Hematoxylin and eosin-stained sections of EDL $(A$ and $B)$ and soleus muscles $(C$ and $D$ ) from 6-mo-old ( $A$ and $C$ ) and 18-moold mice $(B$ and $D)$ are pictured at $\times 10$ magnification. Note the presence of central nuclei and increasing necrosis. 
Table 3. Occurrence of central nuclei in muscles of Sgca-null mice

\begin{tabular}{lccc}
\hline \hline & \multicolumn{3}{c}{ Age } \\
\cline { 2 - 4 } & \multicolumn{1}{c}{$6 \mathrm{mo}$} & $12 \mathrm{mo}$ & $18 \mathrm{mo}$ \\
\hline EDL muscles & & & \\
$\quad$ Males & $76.0 \pm 1.4$ & $70.9 \pm 1.8$ & $74.2 \pm 1.6$ \\
$\quad$ Females & $76.9 \pm 2.1 \dagger$ & $72.3 \pm 1.6$ & $66.9 \pm 2.5^{*}$ \\
SOL muscles & & & \\
$\quad$ Males & $65.5 \pm 2.5 \dagger$ & $61.7 \pm 2.3$ & $54.8 \pm 1.8$ \\
Females & $54.8 \pm 2.7^{*} \dagger$ & $60.1 \pm 2.1 \dagger$ & $43.2 \pm 1.8^{*}$ \\
\hline
\end{tabular}

Values are means \pm SE for the percentages of fibers that contained central nuclei for EDL and SOL muscles of Sgca-null mice. For both EDL and SOL muscles of male and female WT mice of all ages, an overall average of $1.0 \pm$ $0.1 \%$ of fibers contained central nuclei. *Significant $(P<0.05)$ differences between data for a given muscle from age-matched male and female mice; $\dagger$ significant $(P<0.05)$ differences for a given muscle from data for 18 -mo-old gender-matched mice.

(Fig. 6). Whereas muscles of WT mice had very few fibers with central nuclei, extensive central nucleation was observed in both EDL and soleus muscles of Sgca-null mice at all ages (Fig. 6, B and D, and Table 3). Despite persistence in Sgca-null mice of high numbers of fibers with central nuclei, the extent of central nucleation declined with age for EDL muscles $(P=$ $0.003)$ of female mice and for soleus muscles $(P<0.001)$ of both male and female mice (Table 3 ). The significant reduction with age in the number of central nuclei, especially in the soleus muscle, indicates that the regenerative capacity of the $\alpha$-sarcoglycan-deficient muscle may be declining. Finally, more extensive central nucleation in soleus muscles of male compared with female Sgca-null mice suggests that greater regenerative capacity may contribute to our observation of an enhanced ability in male compared with female mice of soleus muscles to adapt to the $\alpha$-sarcoglycan deficiency. The presence in the epimysial space of mononuclear cells, in particular in muscles of older Sgca-null mice, is consistent with previous observations (19) and supports the presence of a progressive ongoing dystrophic process in the Sgca-null mice.

Single fiber CSAs. For male mice, no effects of age on single fiber CSA were observed for either EDL or soleus muscles of Sgca-null or WT mice (Fig. 7, $A$ and $C$ ). Despite no effect of age on the median fiber size, the variability coefficients increased with age more than $30 \%$ for EDL muscles of male Sgca-null mice (Fig. 8A) and nearly $20 \%$ for soleus muscles (Fig. 8B), an effect not observed for WT mice. In addition, for both EDL and soleus muscles, variability coefficients for fiber
A EDL muscles of male mice

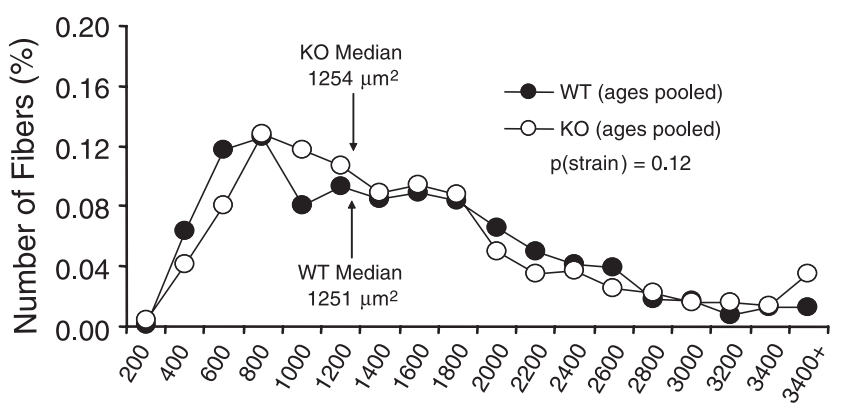

Fiber Size $\left(\mu \mathrm{m}^{2}\right)$

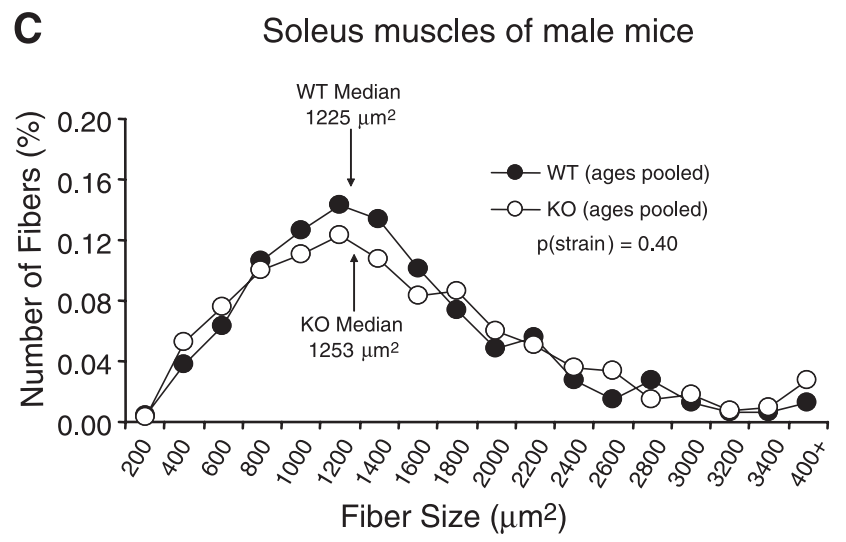

B EDL muscles of female mice
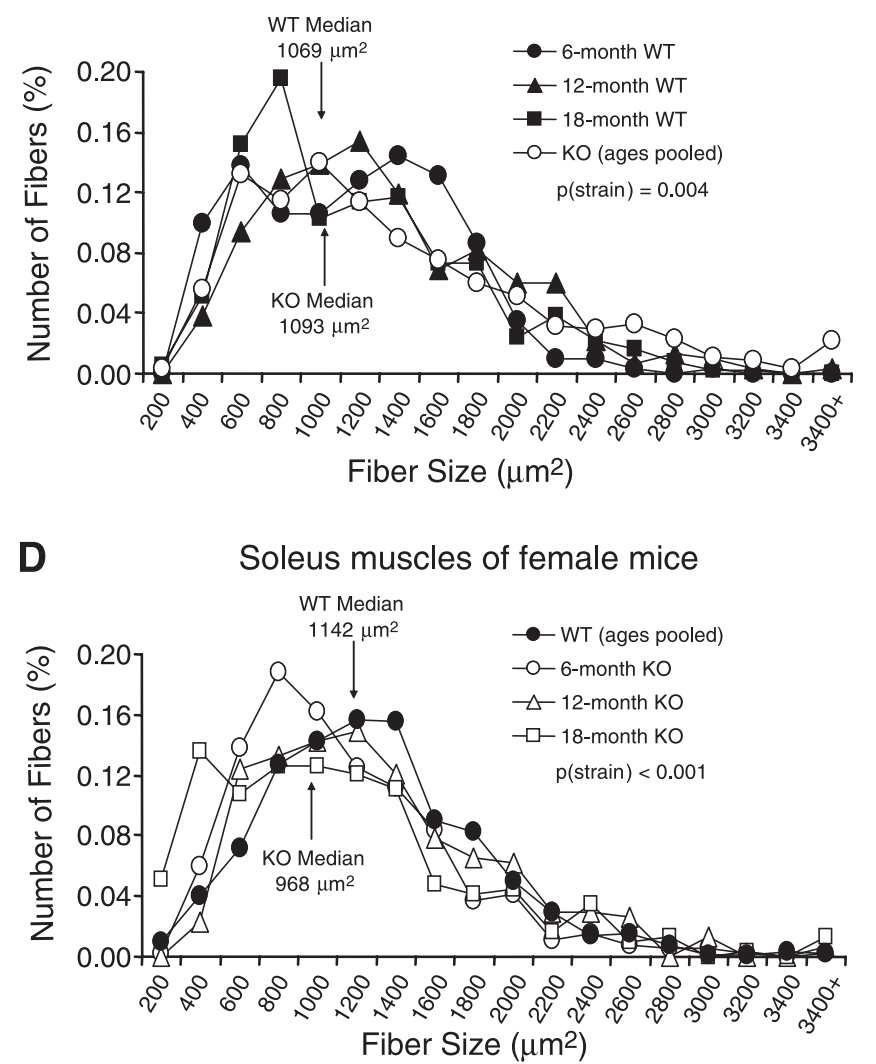

Fig. 7. Frequency distributions of single fiber CSAs for EDL and soleus muscles of Sgca-null (KO) and WT mice. Histograms are presented for the number of fibers of a given CSA (in $\left.\mu \mathrm{m}^{2}\right)$ for $\operatorname{EDL}(A$ and $B)$ and soleus muscles $(C$ and $D)$ of KO and WT mice. Fiber numbers are presented as a percentage of the total fibers measured for male $(A$ and $C)$ and female mice $(B$ and $D)$. For neither EDL $(P=0.12)$ nor soleus $(P=0.08)$ muscles of male mice was there a significant effect of age, so fiber size data from mice of all ages were pooled. For EDL muscles of female WT mice and for soleus muscles of female KO mice, median fiber sizes increased $(P<0.001)$ between 6 and 12 mo and then returned to 6-mo levels at 18 mo. Thus individual distributions are shown for each age, whereas data for EDL muscles of female KO mice and for soleus muscles of female WT mice were pooled across age. Overall median fiber sizes for each muscle are indicated with no differences for males between muscles of KO and WT mice but slightly larger fibers for EDL muscles of female KO compared with WT mice and smaller fibers for soleus muscles of female $\mathrm{KO}$ mice. 
A

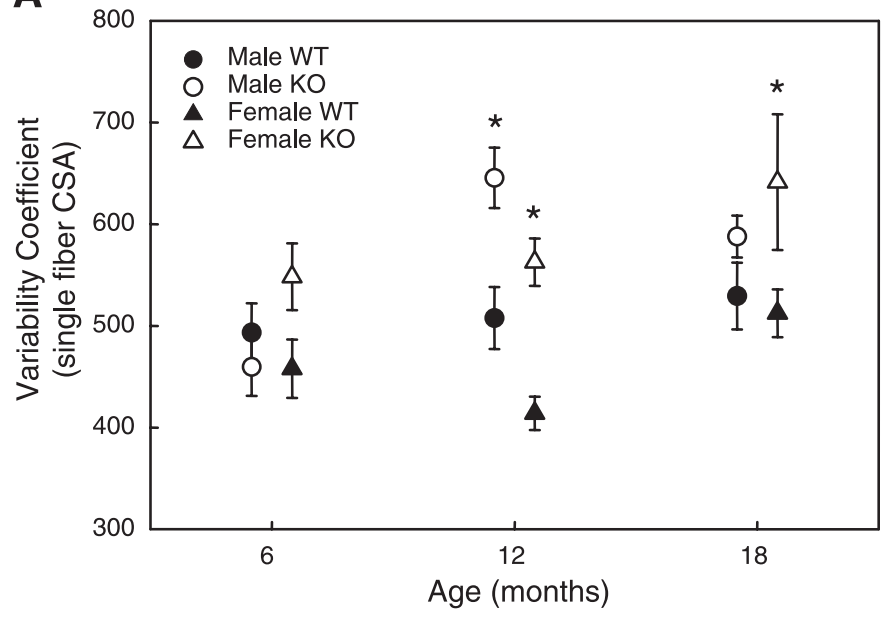

B

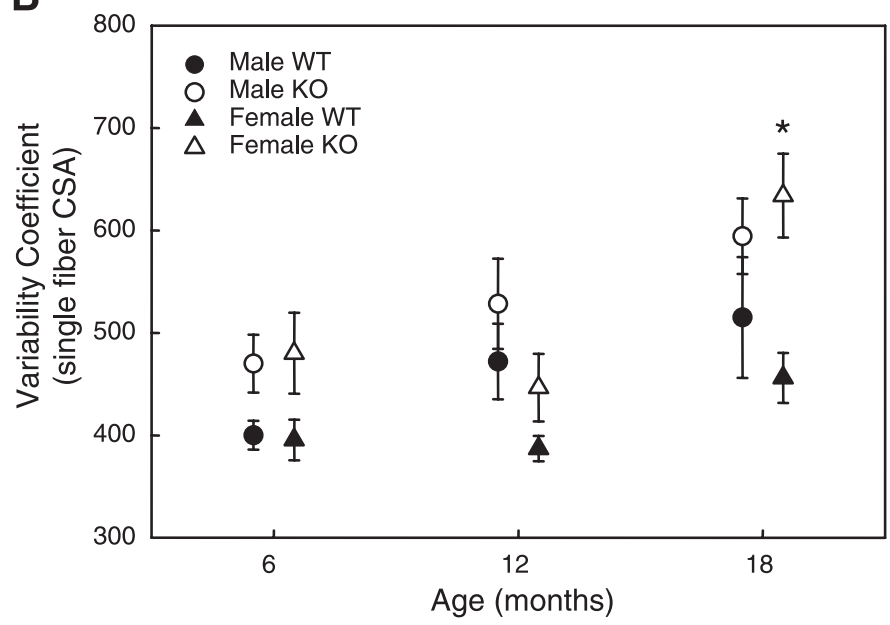

Fig. 8. Coefficients of variation for single fiber CSAs for EDL and soleus muscles of Sgca-null (KO) and WT mice. Data are presented as means $\pm \mathrm{SE}$ for the variability coeffeicients of $\operatorname{EDL}(A)$ and soleus muscles $(B)$ of male and female KO and WT mice at various ages. Values for male mice are offset slightly to the left and those from female mice to the right of the actual ages for clarity of presentation. Whereas there were no effects of age for muscles of WT mice, for KO mice, variability coefficients increased with age for EDL muscles of male mice and for soleus muscles of both male and female mice. Significant differences were also observed between KO and WT mice for both EDL and soleus muscles of both male and female mice with the variability always greater for muscles of $\mathrm{KO}$ mice. ${ }^{*}$ Significant differences between data on age- and gender-matched KO and WT mice $(P<0.05)$.

CSAs were $\sim 13 \%$ greater for muscles of male Sgca-null mice compared with WT mice (overall strain effects: EDL muscles, $P=0.03$; soleus muscles, $P=0.04$ ), although the individual group comparisons showed significant strain effects $(P=$ 0.002 ) only for EDL muscles at 12 mo of age (Fig. 8). The fiber size distributions for male mice, even when pooled across all ages (Fig. 7, $A$ and $C$ ), showed that the higher variability coefficients were due primarily to a greater number of very large fibers in the muscles of Sgca-null compared with WT mice, with no differences in the median fiber sizes for either EDL (WT: 1,251 $\mathrm{mm}^{2}$; Sgca-null: 1,254 $\mathrm{mm}^{2}$ ) or soleus (WT: 1,225 $\mu^{2}$; Sgca-null: 1,253 $\mu^{2}$ ) muscles.

Single fiber CSA increased for EDL muscles in female WT mice between 6 and $12 \mathrm{mo}$ and then returned to the 6-mo level by $18 \mathrm{mo}$, whereas there were no effects of age on fiber size for EDL muscles of female $\mathrm{Sgca}$-null mice (Fig. $7 \mathrm{~B}$ ). For soleus muscles of female mice, the opposite was true, with WT mice showing no effect of age on fiber size and Sgca-null mice demonstrating an increase between 6 and 12 mo followed by a decrease (Fig. 7D). Similar to the fiber CSAs in male mice, the variability coefficients increased with age for both EDL and soleus muscles of female Sgca-null but not WT mice (Fig. 8). Furthermore, the effect of the $\alpha$-sarcoglycan deficiency on the variability in fiber CSA was more dramatic for female than male mice with both EDL and soleus muscles of Sgca-null mice showing $26 \%$ greater variability coefficients $(P<0.001)$ for single fiber CSA than WT mice. Also similar to the findings for male mice, little if any of the larger mass of $\alpha$-sarcoglycandeficient muscles in female mice was due to hypertrophy of individual fibers as the median single fiber CSAs for EDL muscles were similar (Fig. 7B) for Sgca-null $\left(1,093{\mu \mathrm{m}^{2}}^{2}\right)$ and WT mice $\left(1,069 \mu^{2}\right)$ and over $15 \%$ smaller (Fig. $7 D$ ) for soleus muscles of $\mathrm{Sgca}$-null mice $\left(968 \mathrm{\mu m}^{2}\right)$ compared with WT mice $\left(1,142 \mu \mathrm{m}^{2}\right)$.

Fibers from muscles of male mice were on average $20 \%$ larger than those of female mice for both Sgca-null and WT mice, indicating that most of the $\sim 30 \%$ larger muscle masses in male compared with female mice was explained by greater single fiber CSAs. The fiber sizes reported here are well within the range of fiber sizes previously reported for $m d x$ and control mice by other researchers $(5,15,36,55)$.

Total number of fibers. Overall, muscles of Sgca-null mice exhibited greater fiber numbers compared with the WT values with no effect of age for EDL or soleus muscles. For EDL muscles of WT mice, an average of $626 \pm 38$ muscle fibers appeared in a cross section, whereas for Sgca-null mice, EDL muscle cross sections contained an average of $750 \pm 52$ muscle fibers. The average numbers of fibers that appeared in soleus muscle cross sections were $681 \pm 66$ and $514 \pm 39$ for Sgca-null and WT mice, respectively. Similar numbers of fibers have been reported in the literature from cross sections of EDL and soleus muscles of mice (12). Despite no overall effect of age on fiber number for muscles of either Scga-null or WT mice, significant strain $\times$ age interactions were observed such that for EDL muscles there was no difference between fiber counts for muscles of Sgca-null and WT mice at 3 mo of age, but at 12 and 18 mo of age, cross sections from Scga-null mice contained $21 \%$ and $41 \%$ more fibers, respectively, than sections from WT mice. In contrast, soleus muscles of Sgca-null mice showed $\sim 50 \%$ greater fiber numbers than muscles of WT mice at 3 and 12 mo of age, whereas at 18 mo the fiber counts did not differ for muscles of Sgca-null and WT mice.

Branched fibers. Although branched fibers were readily identifiable in both EDL and soleus muscles of Sgca-null mice, the occurrence of branched fibers was low and the branching was less extensive for individual fibers compared with that reported for EDL and soleus muscles of $m d x$ mice at 6-21 mo of age (31). We cannot, however, exclude the possibility that extreme fragility of fiber branches, especially branches with membrane cytoskeletal deficiencies, were broken and not detected.

Connective tissue. Figure 9, $A-D$, shows representative cross sections of EDL and soleus muscles of WT and Sgca-null mice stained with Sirius red. For both EDL and soleus muscles of WT mice, the amount of connective tissue was low, with $\sim 7 \%$ 
Fig. 9. Sirius red staining for connective tissue. Cross sections are shown for sections of $\operatorname{EDL}(A$ and $B)$ muscles at 3 mo of age and soleus muscles $(C$ and $D)$ at $12 \mathrm{mo}$ of age at $\times 100$ magnification for WT and Sgca-null mice. E: pixel percent staining for Sirius red of EDL and soleus muscles from young, adult, and old Sgca-null (shaded bars) and WT (solid bars) mice. Young mice were 3 mo of age, adult mice were 6-12 mo of age, and old mice were 18 mo old. There were significant differences between Sgca-null and WT mice for pixel percentage for both muscles at every age. There was also a significant effect of age for both EDL and soleus muscles of Sgca-null mice and significant strain $\times$ age interactions $(P<0.001)$. Data are presented are means \pm SE. * Significant differences between KO and WT mice $(P<0.05)$.
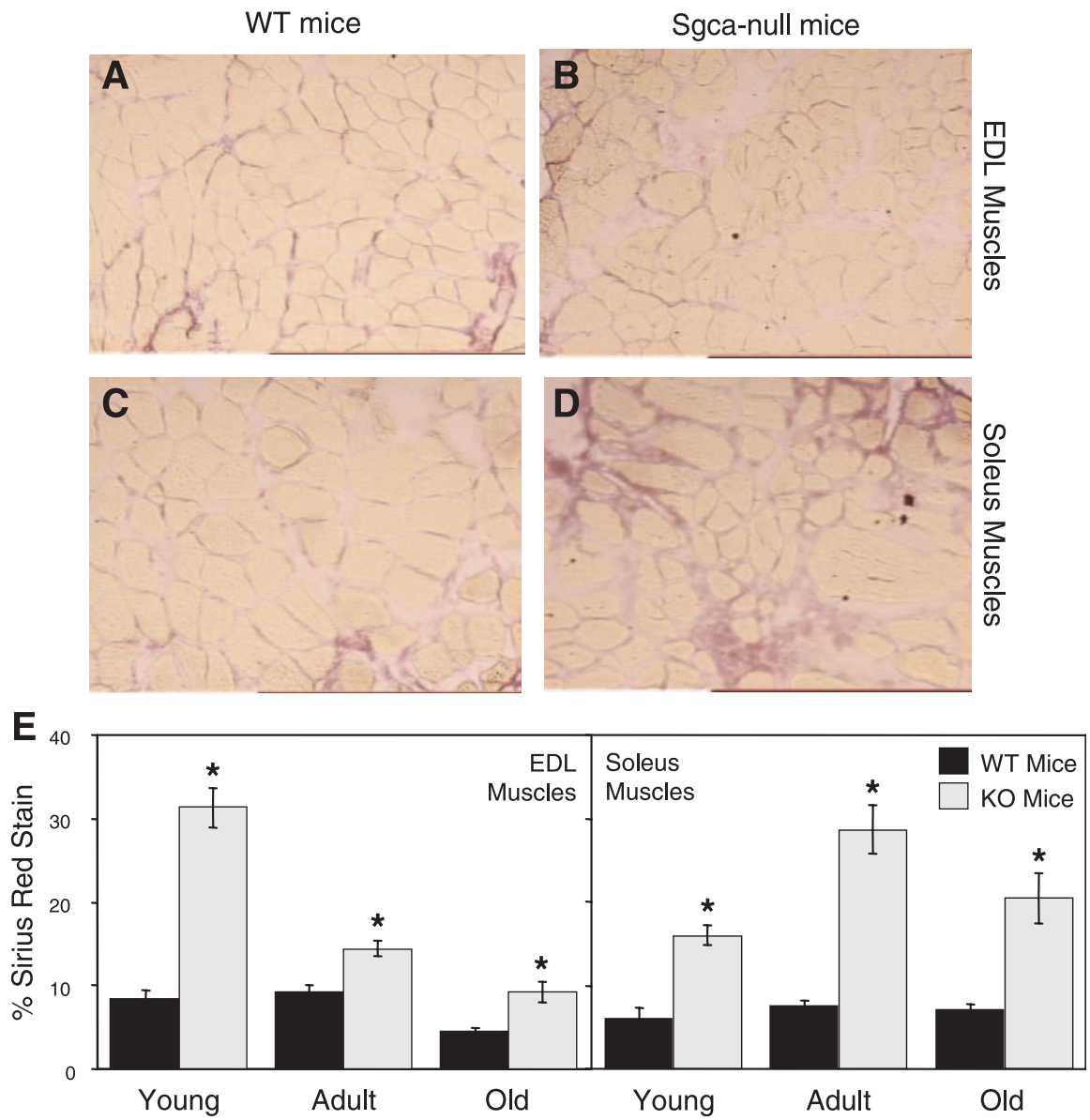

of the cross section staining for Sirius red. In contrast, for Sgca-null mice, the percentage of EDL and soleus muscle cross sections occupied by connective tissue varied somewhat across the ages studied (Fig. 9E). Connective tissue was highest at 3 mo of age in EDL muscles of Sgca-null mice and at $12 \mathrm{mo}$ in soleus muscles. Despite these changes with age, connective tissue was greater at every age for Sgca-null mice than for WT mice, with the percentage of the cross section occupied by connective tissue anywhere from $50 \%$ to nearly $400 \%$ greater for $\alpha$-sarcoglycan-deficient muscles (Fig. $9 E$ ).

Dry mass-to-wet mass ratio. Dry mass-to-wet mass ratios were determined only for muscles of 3-mo-old mice. The dry mass-to-wet mass ratio for EDL muscles of WT mice was $0.25 \pm 0.01$, whereas the value for Sgca-null mice was $0.21 \pm$ 0.01 , indicating water content was greater in the muscles of Sgca-null mice. Similarly, values for soleus muscles were $0.22 \pm 0.01$ and $0.18 \pm 0.01$ for WT mice and Sgca-null mice, respectively. For WT mice, no difference in dry mass-to-wet mass ratio was observed between EDL and soleus muscles. Contrary to the smaller degree of increased mass for soleus muscles of Sgca-null mice, but consistent with generally greater connective tissue content, the soleus muscles showed higher water content than EDL muscles.

\section{Summary of Results}

On the basis of the dry mass-to-wet mass ratios and the percentages of the cross sections stained for Sirius red, estimates were made for young mice for the percentage of the wet mass accounted for by water and extracellular connective tissue. The results of this analysis showed little difference between EDL and soleus muscles of young WT mice, with $76 \%$ and $2 \%$ of the wet mass comprised of water and connective tissue, respectively. The remaining $22 \%$ of the wet mass can be assumed to contain the myofibrillar component as well as a minor contribution by noncontractile cellular components. Connective tissue remained consistently low for WT mice resulting in no changes throughout the age range in the percentages given above. Compared with muscles of WT mice, muscles of young Sgca-null mice showed greater percentages of the wet mass comprised of water $(\sim 80 \%)$ and connective tissue $(\sim 5 \%)$. Consequently, the myofibrillar component contributed a lower percentage $(<15 \%)$ to the wet mass for Sgca-null mice. Also in contrast to the data on WT mice, connective tissue content (Fig. 9E), and likely water content, varied somewhat for Sgca-null mice with age and between EDL and soleus muscles.

For EDL muscles of Sgca-null mice, approximately twothirds of the "hypertrophy" at 3 mo was attributable to increased water and one-third to increased connective tissue, with a negligible contribution of myofibrillar material. For older Sgca-null mice, increased myofibrillar material in EDL muscles contributed a slightly higher percentage to the muscle mass, consistent with slightly higher values for $\mathrm{P}_{\mathrm{o}}$ compared with WT values at the older ages (Fig. 4A). For soleus muscles as well, approximately two-thirds of the "hypertrophy" in young Sgca-null mice was attributable to increased water, but 
the remaining one-third was split roughly $60-40$ between myofibrillar material and connective tissue. The $<20 \%$ of the soleus muscle "hypertrophy" attributable to myofibrillar material accounts for higher $\mathrm{P}_{\mathrm{o}}$ values for $S g c a$-null compared with WT mice at 3 mo (Fig. 4B). Consistent with the drop in $\mathrm{P}_{\mathrm{o}}$ with age for soleus muscles of $\mathrm{Sgca}$-null mice, the contribution of myofibrillar material to the elevated soleus muscle mass was negligible at older ages, and the contributions of connective tissue and water were greater.

\section{DISCUSSION}

Progressive skeletal muscle wasting and weakness are characteristic of patients with primary defects in the expression of one of the sarcoglycan genes (Table 4) $(10,20,34,46,51)$. Despite very early onset of pathology in $S g c a$-null mice (19), Sgca-null mice show an increase in muscle mass relative to WT masses throughout the life span and do not at any age display the muscle wasting that is observed in human LGMD 2D. Both actual myofiber hypertrophy $(25,26,33,36)$ as well as pseudohypertrophy, characterized by proliferation of connective and adipose tissues $(16,33,39)$, have been described in $m d x$ mice and feline and canine models of muscular dystrophy. In the present study, the 50\% and 62\% larger masses of EDL and soleus muscles, respectively, of 3-mo-old Sgca-null compared with age-matched WT mice are in excellent agreement with the $50 \%$ and $70 \%$ greater masses of EDL and soleus muscles of Sgca-null mice at 8 wk reported by Duclos et al. (19). Consistent with our hypotheses, the overall response of eight different muscles of SgCa-null mice, including limb and trunk muscles, was $\sim 40 \%$ greater masses compared with WT values at 6 mo of age. In contrast, the sustained $40 \%$ greater masses of soleus muscles and 30\% increase in EDL muscle mass for Sgca-null mice from 3 to 18 mo were contrary to our hypothesis that Sgca-null mice would experience an acceler- ated loss of muscle mass with age. The ability of muscles in Sgca-null mice to adapt to the deficiency of $\alpha$-sarcoglycan out to $18 \mathrm{mo}$ of age was impressive, particularly in light of the report of Duclos et al. (19) of apparently ongoing and mounting muscle pathology, including single fiber atrophy, hypertrophy, endomysial fibrosis, calcification, and fatty infiltration.

Despite consistently greater masses for muscles of the $\mathrm{Sgca}$ null mice, the roughly equivalent absolute forces generated for much of the life span by muscles of Sgca-null and WT mice are consistent with our conclusion that a relatively small portion of the "hypertrophy" of $\alpha$-sarcoglycan-deficient skeletal muscle was attributable to increased contractile material. Previous attempts to explain low values of specific force for muscles of $m d x$ mice were made by quantifying the actual viable muscle fiber CSA (38). These analyses demonstrated deficits remaining in the "corrected" specific force for bundles of diaphragm muscle fibers from $m d x$ compared with control mice (38). Factors that may explain impaired force generating capacity of "viable" fibers in dystrophic muscle are low force production by fibers expressing embryonic myosin isoforms (45), by fibers undergoing segmental degeneration (48), or by branched fibers (31), changes in excitation-contraction coupling (for a review, see Ref. 9), and/or altered function of the cross-bridges themselves (14). The $30 \%$ lower values for specific $\mathrm{P}_{\mathrm{o}}$ and normalized power reported in the present study for EDL muscles of Sgca-null mice are remarkably similar to the $30 \%$ lower percentage of the EDL muscle wet mass estimated to be composed of contractile material. In fact, after $\mathrm{P}_{\mathrm{o}}$ and power were normalized by the dry mass of contractile material, no differences were observed at 3 mo between Sgca-null and WT mice. These data indicate that the low specific force values observed for limb muscles of Sgca-null mice are explained by shifts in the composition of the muscle such that less of the mass is occupied by contractile material and support the

Table 4. Comparison of the effects of $\alpha$-sarcoglycan and dystrophin deficiencies in Sgca-null and mdx mice and LGMD $2 D$ and DMD patients

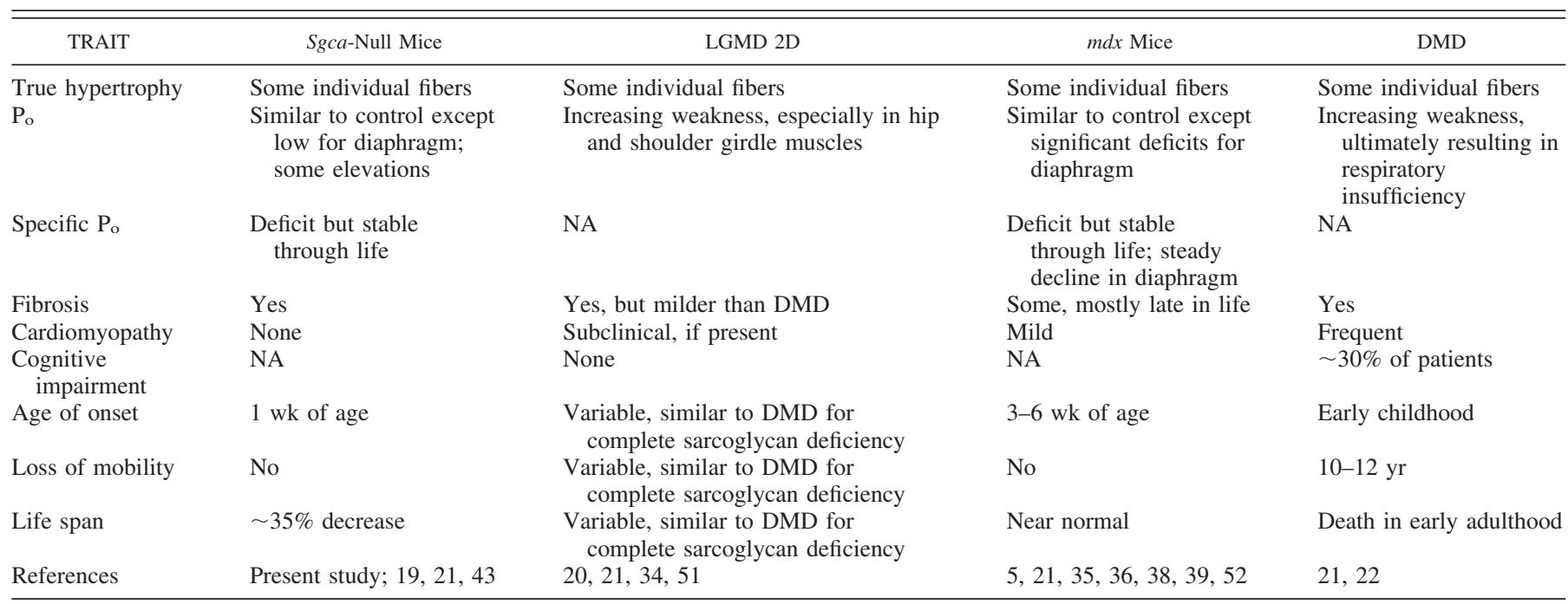

A summary is provided describing various traits associated with deficiencies in the dystrophin-glycoprotein complex in limb girdle muscular dystrophy type 2D (LGMD 2D) and Duchenne muscular dystrophy (DMD) patients as well as Sgca-null and dystrophin-deficient (mdx) mouse models. Traits include true muscle hypertrophy (either an increase in myofiber size or number), maximum force-generating capability $\left(\mathrm{P}_{\mathrm{o}}\right)$, force normalized by muscle cross-sectional area (specific $\mathrm{P}_{\mathrm{o}}$ ), increased intramuscular connective tissue (fibrosis), the development of cardiomyopathy or cognitive impairments, and an effect on age of onset, loss of mobility, and overall life span. 
conclusion that the force-generating capacity of individual fibers is not directly affected. Although these results suggest there is no specific role for the DGC or the sarcoglycan complex in force generation, the elimination in $\alpha$-sarcoglycandeficient mice of the effect of biaxial loading to enhance specific force production by diaphragm muscles (43) supports a role of the sarcoglycan complex to modulate the contractile properties of at least some muscles.

The observation that a large majority of the increased mass of $\alpha$-sarcoglycan-deficient skeletal muscle is connective tissue and water is perhaps not surprising in that connective tissue proliferation is a consistent response across numerous models of muscular dystrophy (Table 4), including DMD (22) and canine X-linked muscular dystrophy (56) and older $m d x$ mice (35). Increases in noncontractile material are uncommon in muscles of control animals without disease. In muscles of control mice, the percentage of connective tissue is very small and stable until the age of about 25 mo (2), and the dry mass-to-wet mass ratio also does not change with age (11), although collagen accumulation has been reported in response to overload $(1,27,57)$. The increased load experienced by the weight-bearing soleus muscle might explain the greater average increase in connective tissue for soleus than for EDL muscles of Sgca-null animals. Increased accumulation of collagen in dystrophic muscles has been attributed to greater transcriptional activity of collagen genes in muscle fibroblasts in response to damage (28). Alternatively, the connective tissue proliferation may be associated directly with the deficiency of the sarcoglycan complex. Support for the hypothesis that connective tissue proliferation is associated directly with sarcoglycan deficiency is provided by the observation that connective tissue accumulation is initiated very early in life in muscles of Sgca-null mice, dystrophic dogs, and to some extent $m d x$ mice and DMD patients $(16,35,42)$.

As observed for limb muscles of $m d x$ mice $(5,36,39)$, single fiber CSAs for EDL or soleus muscles of Sgca-null mice were not greater than those for muscles of WT mice (Table 4). The lack of an increase in average muscle fiber size in Sgca-null mice suggests that any enhanced ability of muscles of Sgcanull mice to generate absolute force is due to an increase in fiber number compared with muscles of WT mice. At least a portion of the hypertrophy of avian muscle in response to overload (3) and of muscles of $m d x$ mice (31) and dystrophindeficient cats (25) appears to involve an increase in muscle fiber number. Although our data indicate that muscles of Sgca-null mice exhibited greater fiber numbers when compared with WT values at all ages studied, these measurements of fiber number were made through single muscle cross sections. Fiber counts made from cross sections cannot distinguish branched portions of the same fiber. Consequently, under circumstances when branched fibers are present, as is the case in $\alpha$-sarcoglycan-deficient muscle, such fiber counts are likely to be inflated. The number of fibers in a muscle can be increased by the splitting of existing fibers, by the generation of new fibers through the proliferation of satellite cells $(30,49)$, or some combination of the two phenomena. High levels of satellite cell activation and muscle regeneration have been reported in several models of muscular dystrophy $(4,40,50)$.

Our findings of higher coefficients of variation for single fiber CSAs for muscles of Sgca-null compared with WT mice indicate the presence of small, regenerating, branched or spilt fibers, and/or large, apparently hypertrophied, fibers as well as fibers with "average" CSAs in the muscles of Sgca-null mice. Previous analyses of fiber sizes in limb muscles of $m d x$ mice have also demonstrated no differences in mean muscle fiber CSAs for $m d x$ and control mice but greater numbers of fibers in $m d x$ mice with large and small diameters $(15,55)$ or CSAs $(5,36,39)$. Likewise, dystrophin-deficient cats had similar mean fiber diameters but much larger variability coefficients for fiber diameters compared with heterozygous or control animals (25). In mammals, muscle hypertrophy typically occurs at the level of individual myofiber hypertrophy as the physiological response to a chronic increase in load (47). Despite little evidence for increases in mean fiber CSA in dystrophic compared with control muscles, significant hypertrophy of individual myofibers and high variability in fiber diameters appear to be hallmarks of many models of muscular dystrophy $(5,19,25,33,39)$. Whether the hypertrophied fibers are in fact responding in a compensatory fashion to an increased load placed on them as a result of adjacent damaged and dysfunctional fibers (36) or represent an indication of an overall defect in the ability of dystrophic skeletal muscle to regulate fiber size is not clear.

Similar to the mild disease of $m d x$ mice $(6,18,36,55)$ compared with DMD patients $(21,22)$, the pathology of Sgcanull mice (Ref. 19 and present study) is mild compared with that of LGMD 2D patients with complete $\alpha$-sarcoglycan deficiency $(20,34,51)$, although $S g c a$-null mice do appear to have a significantly shortened life span as evidenced by our experience of an increase in mortality beyond 18 mo of age (Table 4). The reason for the apparent decrease in life span of Sgca-null mice is not known. Whereas $m d x$ mice display a mild cardiomyopathy (21), none is present in Sgca-null mice despite a reduction of the sarcoglycan complex in cardiac muscle (19). We have observed that older Sgca-null mice appear to experience difficulty with chewing food, a factor that may be associated with the trend toward a decrease in body mass observed for 18-mo-old mice as well as with the increase in mortality. One explanation for the mild phenotype of $m d x$ mice compared with DMD patients is that utrophin, a homologous protein to dystrophin, compensates for the defect in mice more effectively than in human beings. Support for this hypothesis is provided by the severe dystrophic phenotype of $u t r n^{-1-} / m d x$ mice lacking both utrophin and dystrophin $(17,29)$ and the amelioration of the myopathy in these mice by skeletal musclespecific expression of truncated utrophin (44). One might speculate that a similar compensatory mechanism protects muscles of Sgca-null mice but not humans.

The ability to mount an effective muscle regenerative response also appears to be an important factor distinguishing the progression of various forms of muscular dystrophy. The relatively mild diseases in $m d x$ and $S g c a$-null mice as well as the fiber hypertrophy and lack of accumulation of endomysial or perimysial fibrosis in dystrophic cats $(25,50)$ occur in models in which effective muscle regeneration is apparently ongoing and continuous $(5,6,50)$. The observation in the present study of large numbers of centrally nucleated fibers in muscles of Sgca-null mice out to 18 mo of age supports the persistence of active regeneration in the muscles of these mice. In contrast, progressive muscle wasting and weakness and increases in connective tissue observed in dystrophin-deficient dogs $(16,42)$, in the diaphragm muscles of $m d x$ mice (52), and 
in DMD and LGMD patients are associated with a lack of evidence of regenerating fibers. $M d x$ mice deficient in either the early muscle-specific transcription factor MyoD (41) or the myocyte nuclear factor (MNF) selectively expressed in satellite cells (24) exhibit impaired satellite cell function, decreased skeletal muscle regenerative capacity, severe myopathy, and premature death. The results of the studies of MyoD- and MNF-deficient $m d x$ mice support not only the importance of these factors in muscle regeneration but the importance of the regenerative response in the mild dystrophic phenotype of $m d x$ mice. On the basis of these experiments, the function of specific transcription factors or the ability of satellite cells to respond to the factors may play a role in the ability of muscles of $m d x$ and $S g c a$-null mice to respond to dystrophy-causingmutations with a compensatory regenerative response.

In summary, all DGC-based membrane cytoskeletal defects in all species show some form of muscle hypertrophy, either true hypertrophy or pseudohypertrophy, early in the disease process. In $\alpha$-sarcoglycan-deficient skeletal muscles, the portion of the elevated mass that can be considered true hypertrophy is small and variable with age and between muscles. Soleus muscles of $\alpha$-sarcoglycan-deficient mice show some true hypertrophy early in life, but this is not maintained. EDL muscles of these mice actually display some evidence of increasing true hypertrophy with age, primarily in the form of increased fiber number. After the early hypertrophy, different forms of muscular dystrophy diverge with respect to the occurrence, rate, and magnitude of wasting and weakness, but the course of the divergence is not necessarily consistent across species, even under circumstances when the same protein(s) are involved. Consequently, the intrinsic relationship between the hypertrophy on the one hand and the subsequent wasting and weakness on the other hand remains unclear. The results of the present study clearly indicate that the Sgca-null mouse model does not at any age represent the muscle wasting that is observed in human LGMD 2D. Despite disparate phenotypes in sarcoglycan-deficient mice and LGMD 2D patients with the same genetic defect, the Sgca-null mouse holds tremendous value as a tool for establishing the basic function of the sarcoglycan complex and the pathophysiology of sarcoglycandeficient muscular dystrophies.

\section{ACKNOWLEDGMENTS}

The authors acknowledge Carol Davis, Cheryl Hassett, and Jack van der Meulen of the Contractility Core of the Nathan Shock Center at the University of Michigan for assistance in data collection; Andrzej Galecki and Shu Chen of the Older American Independence Center, also at the University of Michigan, for statistical analyses; and John Faulkner for helpful comments on the manuscript.

\section{GRANTS}

This study was supported by the National Institutes of Health and the Muscular Dystrophy Association. K. P. Campbell is an investigator of the Howard Hughes Medical Institute. C. M. Consolino was supported by Cellular and Molecular Approaches to Systems and Integrative Biology Training Grant 5 T32 GM-08322.

\section{REFERENCES}

1. Al Zaid N, Goldspink G, and Williams PE. Increase in collagen concentration in overloaded skeletal muscles. J Physiol 310: 55P, 1980.

2. Alnaqeeb MA and Goldspink G. Changes in fibre type, number and diameter in developing and ageing skeletal muscle. J Anat 153: 31-45, 1987.
3. Alway SE, Gonyea WJ, and Davis ME. Muscle fiber formation and fiber hypertrophy during the onset of stretch-overload. Am J Physiol Cell Physiol 259: C92-C102, 1990.

4. Anderson JE. Dystrophic changes in mdx muscle regenerating from denervation and devascularization. Muscle Nerve 14: 268-279, 1991.

5. Anderson JE, Bressler BH, and Ovalle WK. Functional regeneration in the hindlimb skeletal muscle of the mdx mouse. J Muscle Res Cell Motil 9: 499-515, 1988.

6. Anderson JE, Ovalle WK, and Bressler BH. Electron microscopic and autoradiographic characterization of hindlimb muscle regeneration in the mdx mouse. Anat Rec 219: 243-257, 1987.

7. Betto R, Senter L, Ceoldo S, Tarricone E, Biral D, and Salviati G. Ecto-ATPase activity of $\alpha$-sarcoglycan (adhalin). J Biol Chem 274: 7907-7912, 1999.

8. Blaivas $\mathbf{M}$ and Carlson BM. Muscle fiber branching-difference between grafts in old and young rats. Mech Ageing Dev 60: 43-53, 1991.

9. Blake DJ, Weir A, Newey SE, and Davies KE. Function and genetics of dystrophin and dystrophin-related proteins in muscle. Physiol Rev 82: 291-329, 2002.

10. Bönnemann CG, Modi R, Noguchi S, Mizuno Y, Yoshida M, Gussoni E, McNally EM, Duggan DJ, Angelini C, and Hoffman EP. $\beta$-Sarcoglycan (A3b) mutations cause autosomal recessive muscular dystrophy with loss of the sarcoglycan complex. Nat Genet 11: 266-273, 1995.

11. Brooks SV and Faulkner JA. Contractile properties of skeletal muscles from young, adult and aged mice. J Physiol 404: 71-82, 1988.

12. Brooks SV and Faulkner JA. Contraction-induced injury: recovery of skeletal muscles in young and old mice. Am J Physiol Cell Physiol 258: C436-C442, 1990.

13. Chan YM, Bonnemann CG, Lidov HGW, and Kunkel LM. Molecular organization of sarcoglycan complex in mouse myotubes in culture. J Cell Biol 143: 2033-2044, 1998.

14. Coirault C, Lambert F, Marchand-Adam S, Attal P, Chemla D, and Lecarpentier Y. Myosin motor dysfunction in dystrophic mouse diaphragm. Am J Physiol Cell Physiol 277: C1170-C1176, 1999.

15. Coulton GR, Morgan JE, Partridge TA, and Sloper JC. The mdx mouse skeletal muscle myopathy: I. A histological, morphometric and biochemical investigation. Neuropathol Appl Neurobiol 14: 53-70, 1988.

16. Cozzi F, Cerletti M, Luvoni GC, Lombardo R, Brambilla PG, Faverzani S, Blasevich F, Cornelio F, Pozza O, and Mora M. Development of muscle pathology in canine X-linked muscular dystrophy. II. Quantitative characterization of histopathological progression during postnatal skeletal muscle development. Acta Neuropathol (Berl) 101: 469-478, 2001.

17. Deconinck AE, Rafael JA, Skinner JA, Brown SC, Potter AC, Metzinger L, Watt DJ, Dickson JG, Tinsley JM, and Davies KE. Utrophindystrophin-deficient mice as a model for Duchenne muscular dystrophy. Cell 90: 717-727, 1997.

18. DiMario JX, Uzman A, and Strohman RC. Fibre regeneration is not persistent in dystrophic (MDX) mouse skeletal muscle. Dev Biol 148: 314-321, 1991.

19. Duclos F, Straub V, Moore SA, Venzke DP, Hrstka RF, Crosbie RH, Durbeej M, Lebakken CS, Ettinger AJ, vander Meulen JH, Holt KH, Lim LE, Sanes JR, Davidson BL, Faulkner JA, Williamson R, and Campbell KP. Progressive muscular dystrophy in $\alpha$-sarcoglycan-deficient mice. J Cell Biol 142: 1461-1471, 1998.

20. Duggan DJ, Gorospe JR, Fanin M, Hoffmann EP, and Angelini C. Mutations in the sarcoglycan genes in patients with myopathy. $N$ Engl J Med 336: 618-624, 1997.

21. Durbeej M and Campbell KP. Muscular dystrophies involving the dystrophin-glycoprotein complex: an overview of current mouse models. Curr Opin Genet Dev 12: 349-361, 2002.

22. Emery AEH. Duchenne Muscular Dystrophy. Oxford: Oxford Medical Publications, 1987.

23. Ervasti JM and Campbell KP. A role for the dystrophin-glycoprotein complex as a transmembrane linker between laminin and actin. J Cell Biol 122: 809-823, 1993.

24. Garry DJ, Meeson A, Elterman J, Zhao Y, Yang P, Bassel-Duby R, and Williams RS. Myogenic stem cell function is impaired in mice lacking the forkhead/winged helix protein MNF. Proc Natl Acad Sci USA 97: 5416-5421, 2000.

25. Gaschen F and Burgunder JM. Changes of skeletal muscle in young dystrophin-deficient cats: a morphological and morphometric study. Acta Neuropathol (Berl) 101: 591-600, 2001. 
26. Gashen FP, Hoffman EP, Gorospe JR, Uhl EW, Senior DF, Cardinet GH 3rd, and Pearce LK. Dystrophin deficiency causes lethal muscle hypertrophy. J Neurol Sci 110: 149-159, 1992.

27. Goldspink G and Williams PE. The nature of the increase in passive resistance in the muscle following immobilisation of the mouse soleus. J Physiol 289: 55P, 1979.

28. Goldspink G, Fernandes K, Williams PE, and Wells DJ. Age-related changes in collagen gene expression in the muscles of mdx dystrophic and normal mice. Neuromuscul Disord 4: 183-191, 1994.

29. Grady RM, Teng H, Nichol M, Cunningham C, Wilkinson RS, and Sanes JR. Skeletal and cardiac myopathies in mice lacking utrophin and dystrophin a model for Duchenne muscular dystrophy. Cell 90: 729-738, 1997.

30. Hall-Craggs ECB. The longitudinal division of fibres in overloaded rat skeletal muscle. J Anat 107: 459-470, 1970.

31. Head SI, Williams DA, and Stephenson DG. Abnormalities in structure and function of limb skeletal muscle fibres of dystrophic mdx mice. Proc $R$ Soc Lond B Biol Sci 248: 163-169, 1992.

32. Holt KH, Lim LE, Straub V, Venzke DP, Duclos F, Anderson RD, Davidson BL, and Campbell KP. Functional rescue of the sarcoglycan complex in the BIO 14.6 hamster using delta-sarcoglycan gene transfer. Mol Cell 1: 841-848, 1998

33. Kornegay JN, Cundiff DD, Bogan DJ, Bogan JR, and Okamura CS. The cranial sartorius muscle undergoes true hypertrophy in dogs with golden retriever muscular dystrophy. Neuromuscul Disord 13: 493-500, 2003.

34. Laval SH and Bushby KMD. Limb-girdle muscular dystrophies-from genetics to molecular pathology. Neuropathol Appl Neurobiol 30: 91-105, 2004.

35. Lefaucheur JP, Pastoret C, and Sebille A. Phenotype of dystrophinopathy in old mdx mice. Anat Rec 242: 70-76, 1995.

36. Lynch GS, Hinkle RT, Chamberlain JS, Brooks SV, and Faulkner JA. Force and power output of fast and slow skeletal muscles from mdx mice 6-28 months old. J Physiol 535: 591-600, 2001.

37. Lynch GS, Rafael JA, Chamberlain JS, and Faulkner JA. Contractioninduced injury to single permeabilized muscle fibres from $\mathrm{mdx}$, transgenic mdx, and control mice. Am J Physiol Cell Physiol 279: C1290-C1294, 2000.

38. Lynch GS, Rafael JA, Hinkle RT, Cole NM, Chamberlain JS, and Faulkner JA. Contractile properties of diaphragm muscle segments from old mdx and old transgenic mdx mice. Am J Physiol Cell Physiol 272: C2063-C2068, 1997.

39. Marshall PA, Williams PE, and Goldspink G. Accumulation of collagen and altered fiber-type ratios as indicators of abnormal muscle gene expression in the mdx dystrophic mouse. Muscle Nerve 12: 528-537, 1989.

40. McGeachie JK, Grounds MD, Partridge TA, and Morgan JE. Agerelated changes in replication of myogenic cells in mdx mice: quantitative autoradiographic studies. J Neurol Sci 119: 169-179, 1993.

41. Megeney LA, Kablar B, Garrett K, Anderson JE, and Rudnicki MA. MyoD is required for myogenic stem cell function in adult skeletal muscle. Genes Dev 10: 1173-1183, 1996.
42. Nguyen F, Cherel Y, Guigand L, Goubault-Leroux I, and Wyers M. Muscle lesions associated with dystrophin deficiency in neonatal golden retriever puppies. J Comp Pathol 126: 100-108, 2002.

43. Patel ND, Jannapureddy SR, Hwany W, Chaudry I, and Boriek AM. Altered muscle force and stiffness of skeletal muscles in $\alpha$-sarcoglycandeficient mice. Am J Physiol Cell Physiol 284: C962-C968, 2003.

44. Rafael JA, Tinsley JM, Potter AC, Deconinck AE, and Davies KE. Skeletal muscle-specific expression of a utrophin transgene rescues utrophin-dystrophin deficient mice. Nat Genet 19: 79-82, 1998.

45. Reiser PJ, Moss RL, Giulian GG, and Greaser ML. Shortening velocity and myosin heavy chains of developing rabbit muscle fibres. $J$ Biol Chem 260: 14403-14405, 1985

46. Roberds SL, Leturcq F, Allamand V, Piccolo F, Jeanpierre M, Anderson RD, Lim LE, Lee JC, Tome FM, and Romero NB. Missense mutations in the adhalin gene linked to autosomal recessive muscular dystrophy. Cell 78: 625-633, 1994.

47. Roy RR, Meadows ID, Baldwin KM, and Edgerton VR. Functional significance of compensatory overloaded rat fast muscle. J Appl Physiol 52: 473-478, 1982.

48. Sacco P, Jones DA, Dick JRT, and Vrbova G. Contractile properties and susceptibility to exercise-induced damage in normal and $\mathrm{mdx}$ mouse tibialis anterior muscle. Clin Sci (Lond) 82: 227-236, 1992.

49. Schmalbruch H. Muscle regeneration: fetal myogenesis in a new setting. Bibl Anat 29: 126-153, 1986.

50. Seiler G, Welle M, Busato A, Lin S, and Gaschen FP. Mast cell proliferation and alterations in bFGF amount and localization are involved in the response of muscle to dystrophin deficiency in hypertrophic feline dystrophy. Neuromuscul Disord 11: 56-71, 2001.

51. Sewry CA, Taylor J, Anderson LVB, Ozawa E, Pogue R, Piccolo F, Bushby K, Dubowitz V, and Muntoni F. Abnormalities in $\alpha-, \beta$ - and $\gamma$-sarcoglycan in patients with limb-girdle muscular dystrophy. Neuromuscul Disord 6: 467-474, 1996.

52. Stedman H, Sweeney HL, Shrager JB, Maguire HC, Panettieri RA, Petrof B, Narusawa M, Leferovich JM, Sladky JT, Kelly AM. The mdx diaphragm reproduces the degenerative changes of Duchenne muscular dystrophy. Nature 352: 536-539, 1991.

53. Straub V, Rafael JA, Chamberlain JS, and Campbell KP. Animal models for muscular dystrophy show different patterns of sarcolemmal disruption. J Cell Biol 139: 375-385, 1997.

54. Sweat $\mathbf{F}$ and Puchtler H. Demonstration of amyloid with direct dyes. Arch Pathol 80: 613, 1964.

55. Tanabe Y, Esaki K, and Nomura T. Skeletal muscle pathology in X chromosome-linked muscular dystrophy (mdx) mouse. Acta Neuropathol (Berl) 69: 91-95, 1986.

56. Valentine BA, Winand NJ, Pradhan D, Moise NS, de Lahunta A, Kornegay JN, and Cooper BJ. Canine X-linked muscular dystrophy as an animal model of Duchenne muscular dystrophy: a review. Am J Med Genet 42: 352-356, 1992.

57. Williams PE and Goldspink G. Connective tissue changes in surgically overloaded muscle. Cell Tissue Res 221: 465-470, 1981. 